\title{
STORMWATER RUNOFF DE RODOVIAS E ÁREAS URBANAS: FONTE PRINCIPAL DE CONTAMINAÇÃO POR METAIS NO CÓRREGO DA CASCATA - BOTUCATU (SP)
}

\author{
HIGHWAYS AND URBAN AREAS STORMWATER RUNOFF: MAIN SOURCE OF \\ CONTAMINATION BY METALS IN THE CASCATA BROOK - BOTUCATU (SP)
}

\section{Ivalde BELLUTA ${ }^{1}$, José Carlos COELHO², Sílvio Alexandre de JESUS ${ }^{2}$, Lídia Raquel de CARVALHO ${ }^{1}$, Marcos Henrique Pereira WONDRACEK ${ }^{3}$, Gustavo Rocha de CASTRO ${ }^{1}$, Júlio Toshimi DOYAMA ${ }^{1}$}

\author{
${ }^{1}$ Universidade Estadual Paulista (UNESP). Instituto de Biociências, Distrito de Rubião Junior, S/No - Botucatu SP. Emails: \\ ivalde.belluta@unesp.br; lidia.carvalho@unesp.br; castro@unesp.br; julio.t.doyama@unesp.br \\ ${ }^{2}$ Universidade Estadual Paulista (UNESP). Faculdade de Ciências Agronômicas. Fazenda Experimental Lageado, Rua Doutor José \\ Barbosa de Barros, 1780, Botucatu SP. Email:jose.coelho@unesp.br; silvioaj@hotmail.com \\ ${ }^{3}$ Universidade Federal da Grande Dourados. Dourados - MS. E-mail: marcoswondracek@gmail.com

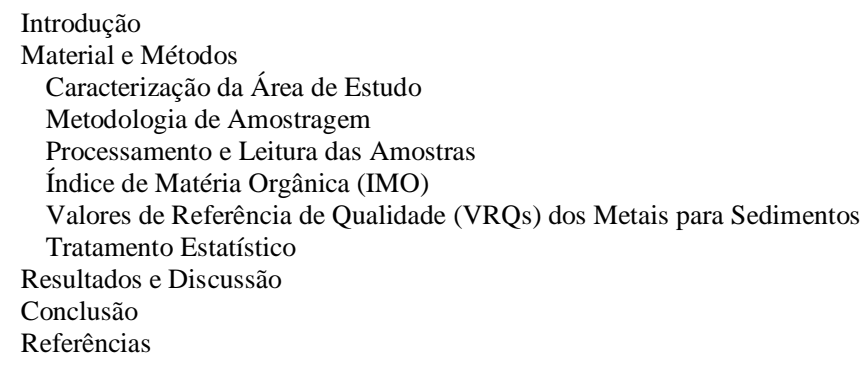

RESUMO - Espécies metálicas encontradas em sedimentos das redes hídricas podem revelar um registro histórico de contaminação. Os objetivos deste estudo foram quantificar os metais $\mathrm{Cd}, \mathrm{Pb}, \mathrm{Cu}, \mathrm{Co}, \mathrm{Cr}, \mathrm{Ni}, \mathrm{Zn}$ e $\mathrm{Sb}$ nos sedimentos, compará-los aos resultados encontrados nos solos na mesma área, avaliar sua relação com a matéria orgânica e os efeitos sobre a biota no cruzamento das rodovias Domingos Sartori $\left(\mathrm{P}_{1}\right)$ e Marechal Rondon $\left(\mathrm{P}_{2}\right)$ com o Córrego da Cascata. As espécies metálicas foram determinadas com espectrômetro de emissão atômica com plasma acoplado indutivamente. Os resultados foram avaliados com teste de Mann Whitney. Como resultado, obtiveram-se concentrações de 1,1 a 8,2 vezes maior no $P_{2}$ em relação ao $P_{1}$. A relação entre metal e índice de matéria orgânica está na ordem decrescente de concentração: $\mathrm{Zn}>\mathrm{Cu}>\mathrm{Cr}>\mathrm{Co}>\mathrm{Ni}>\mathrm{Pb}>\mathrm{Cd}$. Apenas o $\mathrm{Sb}$ não foi detectado nas amostras. Os valores orientadores TEL e PEL do CONAMA e o fator de contaminação estão na ordem $\mathrm{Cd}>\mathrm{Cu}>\mathrm{Zn}$, indicando efeito de toxicidade sobre ecossistema ribeirinho em quase todos os subpontos das rodovias. Os resultados embasam o monitoramento da stormwater runoff em áreas urbanas e rodovias para a conservação e proteção do Córrego da Cascata.

Palavras-chave: Valores orientadores; Toxicidade; Ecossistemas ribeirinhos; Sedimentos; Sub-bacia hidrográfica.

\begin{abstract}
Metal species found at the sediments of water network may reveal a historical record of contamination. The objectives of this study were to quantify the metals $\mathrm{Cd}, \mathrm{Pb}, \mathrm{Cu}, \mathrm{Co}, \mathrm{Cr}, \mathrm{Ni}, \mathrm{Zn}$ and $\mathrm{Sb}$ in the sediments, to compare them with the results found in soils in the same area, to evaluate their relationship with the organic matter and the metal effects on the biota at the intersections of the Domingos Sartori $\left(S_{1}\right)$ and Marechal Rondon $\left(S_{2}\right)$ highways with the Cascata Brook. The determination of the metal species was performed using an atomic emission spectrometer with inductively coupled plasma. The results were statistically evaluated using Mann Whitney test. According to the results, the concentrations were in the range from 1.1 to 8.2 times higher in $\mathrm{P}_{2}$ than in $\mathrm{P}_{1}$. The relation between metal and organic matter index is in the decreasing order of concentration: $\mathrm{Zn}>\mathrm{Cu}>\mathrm{Co}>\mathrm{Cr}>\mathrm{Ni}>\mathrm{Pb}>\mathrm{Cd}$. Only $\mathrm{Sb}$ was not detected in the samples. The guide values TEL and PEL of CONAMA and contamination factor presented order of contamination $\mathrm{Cd}>\mathrm{Cu}>\mathrm{Zn}$, indicating the effect of toxicity on the riparian ecosystem, in almost all subsits of highways. The results are the basis for monitoring the stormwater runoff quality of urban areas and highways for the purpose of conserving and protecting the Cascata Brook. Keywords: Guiding values; Toxicity; Riparian ecosystems; Sediments; Subwatershed.
\end{abstract}

\section{INTRODUÇÃO}

Nos últimos anos, a comunidade científica internacional vem se preocupando com os efeitos da contaminação ambiental no mundo e motivando pesquisas com solos, sedimentos, águas superficiais e subterrâneas, em nível local, através de estudos em bacias hidrográficas.

Na União Européia, a Diretiva 2000/60/EC legisla sobre recursos hídricos e define princípios básicos de proteção ambiental para o controle da fonte de contaminação das águas subterrâneas e superficiais de uma bacia hidrográfica (THE EUROPEAN PARLIAMENT AND OF THE COUNCIL OF THE EUROPEAN UNION, 2000). Baseado nessas diretivas, Yannopoulos et al. (2013) propõem medidas de aceitação internacional (Best management practices - 
BMP) como plano de gestão de poluentes oriundos do escoamento de águas pluviais (stormwater runoff). O plano estrutural, por exemplo, tem por base as edificações físicas utilizadas para retardar, reter ou absorver poluentes para que não atinjam o corpo d'água. O plano não estrutural, considerado mais simples e economicamente viável, segue regras e regulações para prevenir ou restringir a carga de poluentes por meio de práticas de controle na fonte de contaminação, como limpeza de pavimentos, redução do uso de substâncias poluidoras, educação ambiental urbana, entre outras. A implementação dos dois planos juntos pode alcançar melhor resultado. Segundo o mesmo autor, além de vários países da União Européia, os Estados Unidos e Canadá já estão em andamento com políticas semelhantes.

No Brasil, vários estudos dessa natureza vêm sendo desenvolvidos devido ao potencial iminente de contaminação dos recursos hídricos. Alguns desses estudos indicam altos níveis de particulados e de espécies metálicas presentes na atmosfera em regiões de intenso tráfego de veículos, como acontece em grandes centros urbanos do Brasil e do mundo (Hoff Brait \& Antoniosi Filho, 2010). Como exemplo, no Recife (PE), foram utilizadas plantas epífitas para avaliar a correlação entre a precipitação de particulados nas rodovias e a densidade de veículos (Santos et al., 2013).

Em estudos sobre quantificação do desgaste de freios automotivos, Garcias \& Sottoriva (2010) demonstraram que a poluição difusa por espécies metálicas ocorre devido ao elevado número de veículos nas rodovias. Duarte (2003), Figueiredo (2011) e Silva et al. (2014) encontraram produtos da combustão de veículos automotores expelidos pelos escapamentos, resíduos do desgaste de peças, pneus, pavimentos asfálticos e fluidos veiculares em rodovias e áreas urbanas. Esses resíduos acumulam-se no asfalto e, com a precipitação das chuvas, são carreados como fonte difusa de poluição, que, ao atingir o ecossistema aquático, agregam-se aos sedimentos de fundo do corpo d'água. Outros estudos que abordam essa questão foram realizados por Pereira et al. (2007), Poleto \& Merten (2008), Martinez (2010), Alves et al. (2010), Poleto \& Cardoso (2012), Silva (2014).

Os sedimentos advindos de fontes difusas e de diversas origens precipitam nos canais fluviais, sendo também chamados sedimentos de corrente, de fundo e ativos de drenagem. Tais sedimentos caracterizam os processos químicos e físicos que ocorrem numa bacia hidrográfica (Torres et al., 2005). Para Esteves \& Guariento (2011), nos ecossistemas fluviais, a carga total de espécies metálicas depende de características geológicas e ecológicas das bacias de drenagem e do tipo de atividade humana praticado na proximidade da bacia. Segundo Baird \& Cann (2011), as fontes naturais ou antrópicas em determinada região e a sua retirada e posterior análise podem resultar num registro histórico de contaminação. Segundo Esteves \& Guariento (2011), o resultado da interação de todos os processos que ocorrem em uma bacia hidrográfica funciona como um grande banco de dados e reservatório na retenção de espécies metálicas.

Espécies metálicas e compostos orgânicos podem ser liberados na ocorrência de alterações das características físico-químicas dos corpos d'água, sendo então transferidos para os organismos que habitam a região. Com a utilização desses corpos d'água para áreas de irrigação, ocorre contaminação da biota aquática e, consequentemente, do próprio ser humano (Baird \& Cann, 2011).

Segundo Mazon et al. (2002), os efeitos das espécies metálicas nos ecossistemas aquáticos vão desde a contínua redução nos níveis de crescimento das populações, com a redução do índice de reprodução e o aumento da mortalidade, até a eliminação completa da biota. Portanto, a proteção e a manutenção da qualidade dos sedimentos são um dos propósitos de todo gerenciamento de águas.

Em Botucatu (SP), foram realizadas análises de metais em amostras de água, solos e sedimentos coletadas próximo a corpos d'água sob a influência de contaminação difusa de importantes rodovias. Os estudos dessas análises, descritos em Belluta et al. (2008), Belluta et al. (2014) e Belluta et al. (2018), revelaram preocupação sobre possíveis impactos nos processos químicos, físicos e biológicos da subbacia hidrográfica local.

Localizada a oeste da cidade de Botucatu, a sub-bacia do Córrego da Cascata recebe águas de escoamento das chuvas oriundas de rodovias e áreas urbanas, que podem estar impactando também a qualidade da água dos seus principais afluentes, como o Córrego Água Fria, o Ribeirão Lavapés e o Rio Capivara, até atingir o reservatório de Barra Bonita. 
Dessa maneira, os objetivos do presente estudo foram: quantificar os metais Cd (cádmio), $\mathrm{Pb}$ (chumbo), $\mathrm{Cu}$ (cobre), $\mathrm{Co}$ (cobalto), $\mathrm{Cr}$ (crômio), Ni (níquel), $\mathrm{Zn}$ (zinco) e $\mathrm{Sb}$ (antimônio) nos sedimentos e avaliar sua relação com a matéria orgânica (MO) acumulada nos cruzamentos das rodovias Domingos Sartori e Marechal Rondon com o Córrego da Cascata; comparar os resultados obtidos àqueles já encontrados nos solos na mesma área de estudo; analisar o nível de contaminação provocada pela água escoada das rodovias; identificar possíveis fontes secundárias relacionadas à presença de metais a partir da linha de divisor de águas da sub-bacia; e analisar os efeitos adversos sobre a biota.

\section{MATERIAIS E MÉTODOS}

\section{Caracterização da Área de Estudo}

A área de estudo está localizada na sub-bacia do Córrego da Cascata, na região oeste de Botucatu (SP), e é cortada longitudinalmente pela Rodovia Domingos Sartori $\left(\mathrm{P}_{1}\right)$ e transversalmente pela Rodovia Marechal Rondon $\left(\mathrm{P}_{2}\right)$.

A sub-bacia do Córrego da Cascata, apresenta o ponto mais alto do Morro de Rubião Júnior, com $920 \mathrm{~m}$ de altitude, e está sobre o principal divisor de águas das bacias hidrográficas do Paranapanema e do Tietê (SOSCUESTA, 2013). À jusante forma-se o lago do Parque das Cascatas, no km 2 da Rodovia Domingos Sartori, que está em processo de assoreamento.

$\mathrm{Na}$ foz do córrego da confluência do Córrego Água Fria até sua foz, está o Rio Lavapés, até atingir a represa de Barra Bonita, no Rio Tietê. O córrego tem $4,76 \mathrm{~km}$ até sua foz, com vários tributários que desembocam no Córrego Água Fria, seguido do Ribeirão Lavapés até atingir o reservatório de Barra Bonita, no Rio Tietê (Figura 1). Os Latossolos e os ARGISSOLOS VERMELHO-AMARELO Distróficos (LVAd e AVAd) são predominantes na região.

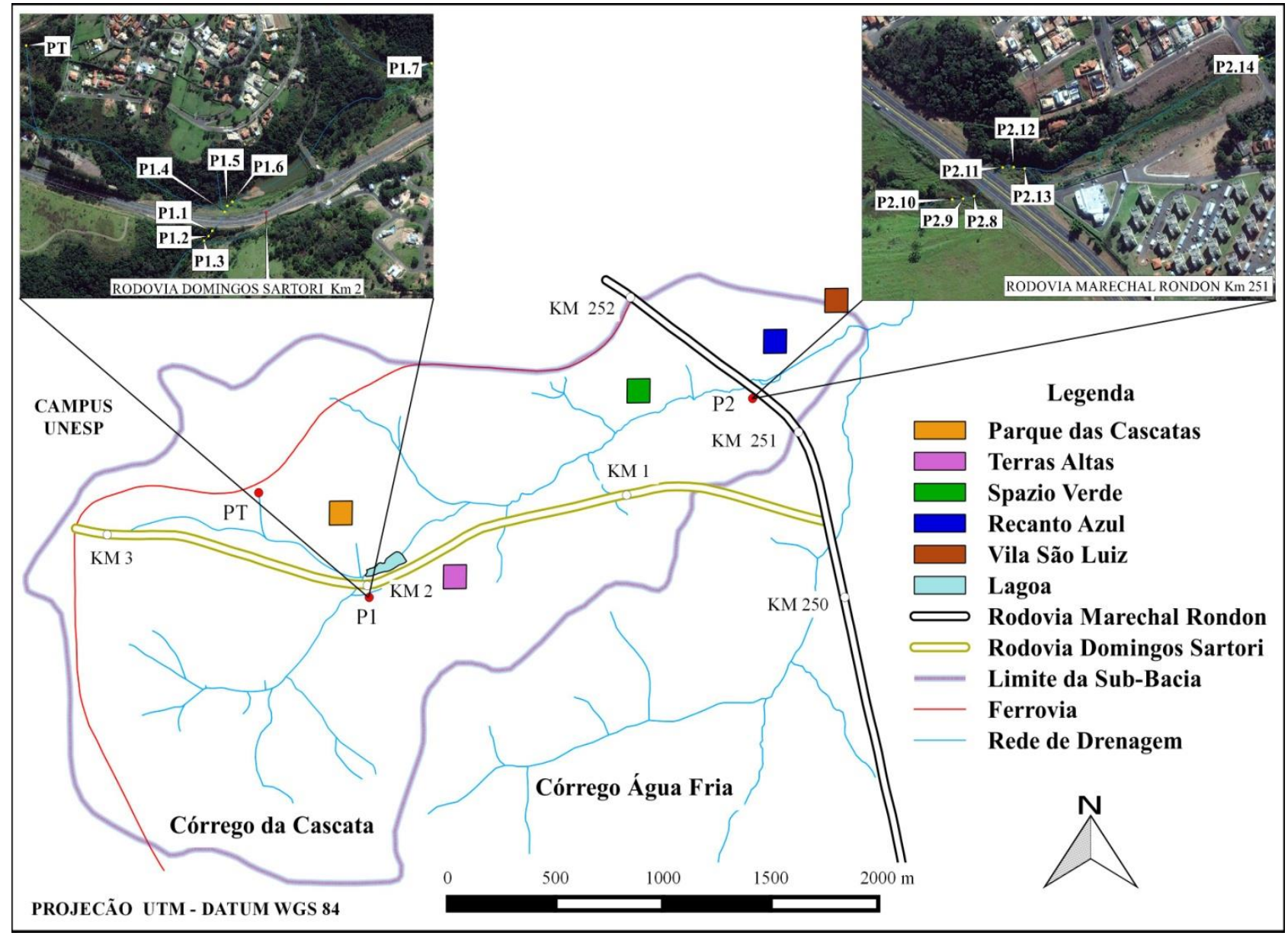

Figura 1 - Localização da área da sub-bacia do Córrego da Cascata, sua rede de drenagem, pontos e de amostragem $\left(\mathrm{P}_{1}\right.$ e $\left.\mathrm{P}_{2}\right)$ e seu principal afluente (Córrego Água Fria). Adaptado de Belluta et al. (2018).

\section{Metodologia de Amostragem}

A única coleta das amostras de sedimentos ocorreu em 12 de maio de 2014. Os dados pluviométricos anteriores a essa data não ultrapassaram $116.0 \mathrm{~mm}$ e nos últimos 20 dias que antecederam a coleta, não houve precipitação 
pluviométrica $(0,0 \mathrm{~mm})$. Esses dados foram obtidos pelo Departamento de Solos e Recursos Ambientais da FCA-Unesp.

$\mathrm{O}$ estudo e a escolha dos pontos de amostragem foram realizados com base nas informações topográficas da área espacial da sub-bacia do Córrego da Cascata com auxílio dos mapas hipsométricos (Figura 2) e de relevo (Figura 3), para subsidiar a avaliação ambiental e compreender a dinâmica hídrica local.

O mapa hipsométrico representa a elevação da área em estudo através das cores ou sistema de graduação de cores. Já o mapa de relevo foi uma representação tridimensional de um terreno com dimensão vertical exagerada, o que facilita de forma eficiente a realidade local do terreno.

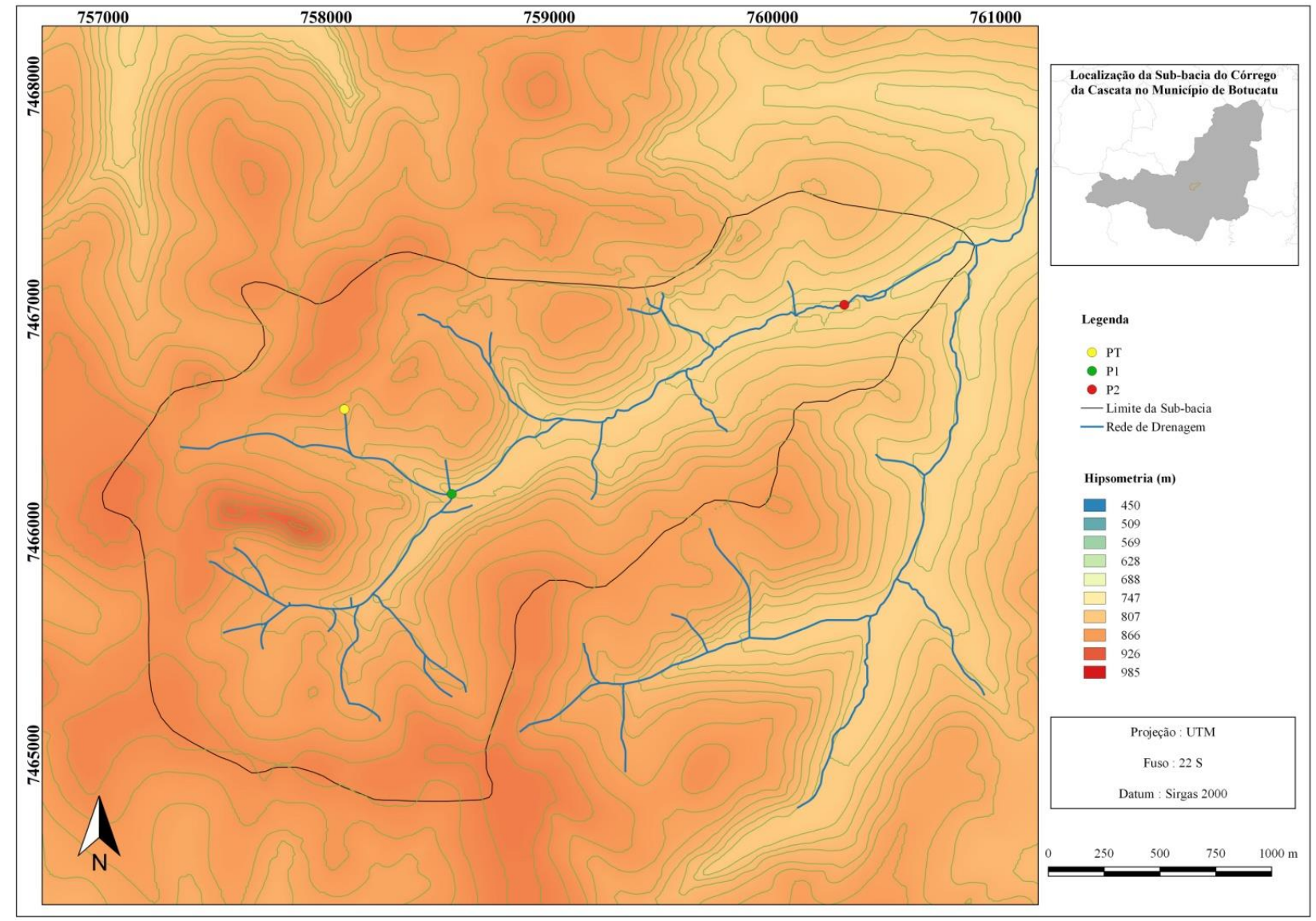

Figura 2 - Mapa hipsométrico da sub-bacia do Córrego da Cascata.

No $\mathrm{P}_{1}$, as coordenadas $\mathrm{x}=758.535,000$ e $\mathrm{y}=7.466 .118,000$, obtidas pelo Sistema de Projeção UTM, datum WGS 84, zona $22 \mathrm{~S}$, com equipamento GPS (Global Positioning System) da marca Garmin, foi subdividido em 3 subpontos perpendiculares à rodovia Domingos Sartori e em cada lado da pista de rolagem, distanciados entre si com as seguintes medidas a partir do término lateral da pista de rolagem: $11 \mathrm{~m}, 26 \mathrm{~m}$ e $41 \mathrm{~m}$. Os subpontos foram identificados a montante como $\mathrm{P}_{1}$ $\left(\mathrm{P}_{1.1}, \mathrm{P}_{1.2}\right.$ e $\left.\mathrm{P}_{1.3}\right)$ e a jusante $\left(\mathrm{P}_{1.4}, \mathrm{P}_{1.5}, \mathrm{P}_{1.6}\right.$ e $\left.\mathrm{P}_{1.7}\right)$. O ponto testemunho $\left(\mathrm{P}_{\mathrm{T}}\right)$ foi demarcado em uma das nascentes, sem fluxo de veículos ou outra interferência antrópica, cujas coordenadas foram: $\mathrm{x}=758.082,050$ e $\mathrm{y}=7.466 .551,640$ (Figura 1).

No $\mathrm{P}_{2}$, as coordenadas foram $\mathrm{x}=760.336,000 \mathrm{e}$ $\mathrm{y}=7.467 .023,000$, e os subpontos localizados a montante, foram dispostos perpendicularmente à Rodovia Marechal Rondon, e identificados como
$\mathrm{P}_{2.8}, \mathrm{P}_{2.9}$ e $\mathrm{P}_{2.10}$ e a jusante $\mathrm{P}_{2.11}, \mathrm{P}_{2.12}, \mathrm{P}_{2.13}$ e $\mathrm{P}_{2.14}$ (Figura 3).

Os subpontos $\quad \mathrm{P}_{1.7} \quad(\mathrm{y}=759.066,300 \quad \mathrm{e}$ $\mathrm{x}=7.466 .507,460) \quad$ e $\quad \mathrm{P}_{2.14} \quad(\mathrm{y}=760.725,950 \quad$ e $\mathrm{x}=7.467 .209,980) \quad$ foram amostrados respectivamente a uma distância de $620 \mathrm{~m}$ e $400 \mathrm{~m}$ das rodovias (Figura1 1).

\section{Processamento e Leitura das Amostras}

Foi utilizado o corer sampler para coletar 1 (uma) porção de sedimento em cada subponto a uma profundidade entre 10 e $15 \mathrm{~cm}$ no leito do Córrego da Cascata e armazenada separadamente em saco plástico para processamento no laboratório do Departamento de Química do Instituto de Biociências da Universidade Estadual de São Paulo (Unesp), campus de Botucatu. Assim, o total de 15 amostras foi seca em estufa com circulação de ar a $80{ }^{\circ} \mathrm{C}$ e homogeneizada em tamis, tendo fração inferior a $75 \mu \mathrm{m}$. Em seguida, foram separadas 3 
alíquotas (três repetições) de cada uma dessas amostras, que totalizaram 45 , e submetida a mineralização da matéria orgânica (digestão da amostra) e encaminhadas para leitura no
Departamento de Solos e Recursos Ambientais da FCA-Unesp.

A digestão das amostras seguiu a ordem apresentada no fluxograma (Figura 4).

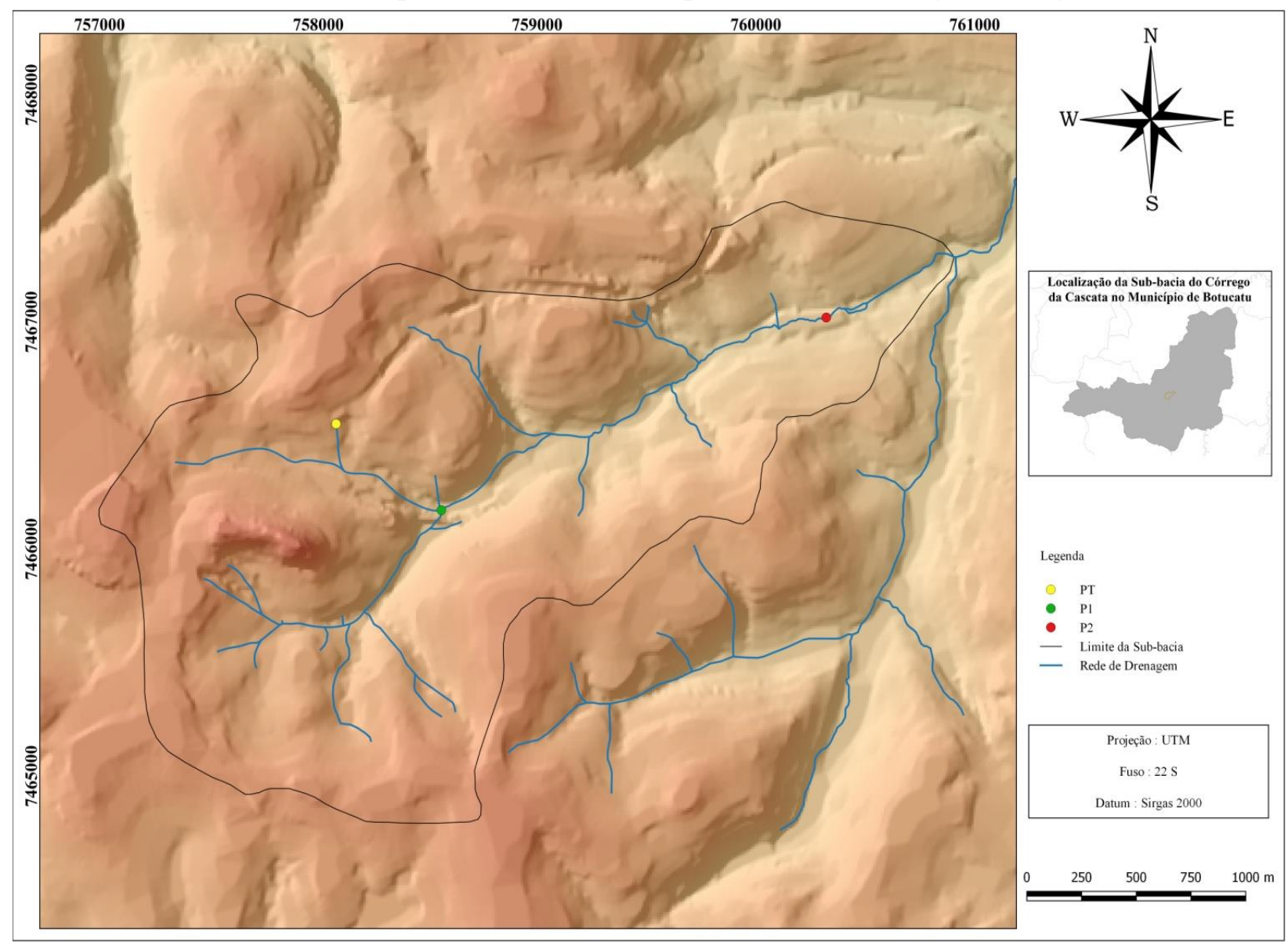

Figura 3 - Mapa de relevo da sub-bacia do Córrego da Cascata.

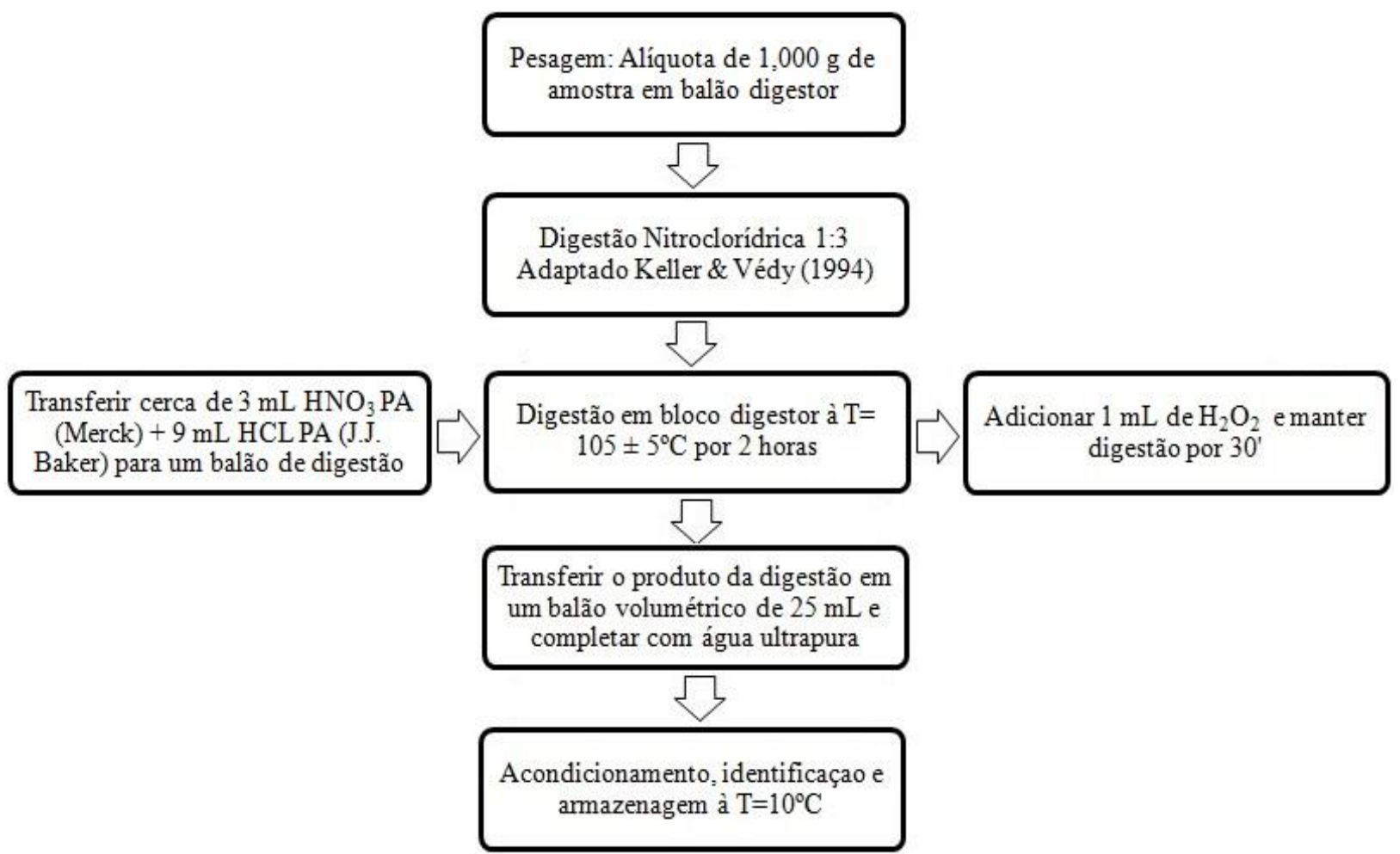

Figura 4 - Fluxograma da digestão das amostras de sedimentos do Córrego do Cascata. 
De acordo com Minello et al. (2009), a digestão aberta é tão eficiente e confiável quanto os outros dois métodos quando se trata de analitos não voláteis (USEPA - 3050B). Não houve perdas dos analitos pelo efeito de arraste de vapor.

Para evitar contaminação cruzada, todos os recipientes utilizados no processamento das amostras foram descontaminados por banho de imersão em solução de $\mathrm{HNO}_{3}$ a $10 \%$ (v/v) por 48 horas (Brandão et al., 2011). As amostras foram encaminhadas ao Departamento de Solos e Recursos Ambientais da Faculdade de Ciências Agronômicas da Universidade Estadual de São Paulo (FCA-Unesp).

Os analitos standard (Quimlab Produtos de Química Fina Ltda) para os elementos estudados $\mathrm{Cd}, \mathrm{Pb}, \mathrm{Cu}, \mathrm{Co}, \mathrm{Cr}, \mathrm{Ni}, \mathrm{Zn}$ e $\mathrm{Sb}$, foram rastreados pelo National Institute of Standard and Tecnology (NIST). O manual do fabricante Perkin Elmer modelo Optima 8300 descreve as configurações para a determinação dos metais em estudo. A exatidão do espectrômetro de emissão atômica com plasma acoplado indutivamente é conferida a cada 10 leituras das amostras com uma leitura de um padrão de concentração intermediária para garantir o funcionamento do equipamento nas condições normais em relação à curva analítica.

\section{Índice de Matéria Orgânica (IMO)}

Cerca de $1,0 \mathrm{~g}$ de cada amostra de sedimento foi peneirada, pesada e transferida para uma cápsula de porcelana. O carbono orgânico da amostra foi determinado pela diferença de massa antes e após a calcinação em mufla à temperatura de $550{ }^{\circ} \mathrm{C}$ durante 4 horas (Cotta, 2003).

Valores de Referência de Qualidade(VRQs) dos Metais para Sedimentos

Os resultados dos metais neste estudo foram comparados aos VRQs sugeridos pela agência ambiental internacional National Oceanic and Atmospheric Administration - NOAA (Buchiman, 2008), com adaptação do Conselho Nacional do Meio Ambiente - CONAMA (CONAMA, 2004), com os seguintes valores orientadores: TEL (Threshold Infecto Level), PEL (Probable Effect Level) e o SEL (Severe Effect Level). Foi também determinado o Fator de Contaminação (FC) para espécies metálicas com o propósito de identificar os locais que se afastam das condições naturais. De acordo com Hakanson (1980), o FC é determinado pela razão entre a concentração do elemento no sedimento superficial e a concentração background local. Na falta deste, optou-se por utilizar critérios estabelecidos por Beló et al. (2010), representados pelos valores globais ou médios mundial (VMM) apresentados por Kabata-Pendias (2010), onde os pontos de amostragem inferiores a 1,0 indicam "Baixa" contaminação; os valores entre 1,01 e 3,0 são indicativos de contaminação "Moderada"; os valores entre 3,01 e 6,0 são de contaminação "Considerável"; e os valores maiores que 6,01 são indicativos de "Alta" contaminação.

\section{Tratamento Estatístico}

A análise estatística foi feita por análise de variância seguida do teste de Mann Whitney, no nível de 5\% de significância, para comparação das concentrações. Foram elaborados gráficos BoxWhisker-plot (Gráfico de Caixas) para apresentar a dispersão e assimetria dos dados das variáveis estudadas que contém informações relativas ao primeiro quartil (25\% dos dados estão abaixo desse valor), Mediana (50\% dos valores) e terceiro quartil (75\% dos valores), além de pontos discrepantes denominados outliers (Sokal \& Rohlf, 1995). Desta maneira o Gráfico de Caixas exibirá um sumário completo dos dados de cada variável de forma simples.

\section{RESULTADOS E DISCUSSÃO}

O período que antecedeu as coletas das amostras de sedimentos na região da sub-bacia do Córrego da Cascata não sofreu influência de chuvas. O total pluviométrico em maio/2014 foi de 71,8 mm, considerado inferior em relação aos meses anteriores e, nos últimos 20 dias que antecederam as coletas (junho/2014), não ocorreu precipitação ( $0,0 \mathrm{~mm}$ de chuva).

A análise do mapa contendo as classes hipsométricas (Figura 2) e a imagem de relevo (Figura 3), mostram que o escoamento das águas pluviais desemboca no rio principal nas cotas mais baixas da sub-bacia. No $\mathrm{P}_{1}$ as cotas variam de 747 e 807 e no $\mathrm{P}_{2}$ entre 688 e 747 e as rodovias e áreas urbanas (condomínios) (Figura 1), localizadas na linha do divisor de águas, foram as que mais contribuíram para a composição dos sedimentos.

Segundo a avaliação morfométrica relativa ao relevo e à drenagem realizada na mesma área de estudo, Belluta et al (2014), revelaram que a forma da sub-bacia apresenta baixa propensão a enchentes, escoamento rápido e significativa contribuição no assoreamento do lago localizado a jusante da rodovia Domingos Sartori (Figura 1), devido ao resultado direto da 
intervenção antrópica.

O gráfico Box plot (Figura 5) apresenta a variação e a amplitude (dispersão) das concentrações dos metais analisados em relação às rodovias. $\mathrm{O}$ distanciamento das medianas do conjunto de cada tratamento (50\% dos valores) revela que todos os metais variaram estatisticamente (outliers) e a rodovia Marechal Rondon $\left(\mathrm{P}_{2}\right)$ apresentou maiores concentrações em relação ao da Domingues Sartori $\left(\mathrm{P}_{1}\right)\left(\mathrm{P}_{2}>\mathrm{P}_{1}\right)$. Em função disso, optou-se por avaliar o conjunto de resultados pela razão $\mathrm{P}_{2} / \mathrm{P}_{1}$ em relação a cada metal analisado, o que indicou variação de 1,1 a 8,2 vezes maior no $\mathrm{P}_{2}$ em detrimento do $\mathrm{P}_{1}$, com elevação considerável dos metais $\mathrm{Cu}$ e $\mathrm{Zn}$. Estes resultados foram similares aos obtidos em estudo realizado por Belluta et al. (2018) na mesma área e com base nos mesmos subpontos, cuja variação foi de 1,2 a 11,0 vezes maior no $\mathrm{P}_{2}$ em relação ao $\mathrm{P}_{1}$, com elevação dos teores dos mesmos metais ( $\mathrm{Cu}$ e $\mathrm{Zn}$ ). Em ambos os estudos, dos metais analisados, apenas o $\mathrm{Sb}$ teve resultados inferiores ao limite de detecção da técnica empregada $(<1,0$ $\left.\mathrm{mg} \cdot \mathrm{kg}^{-1}\right)$.

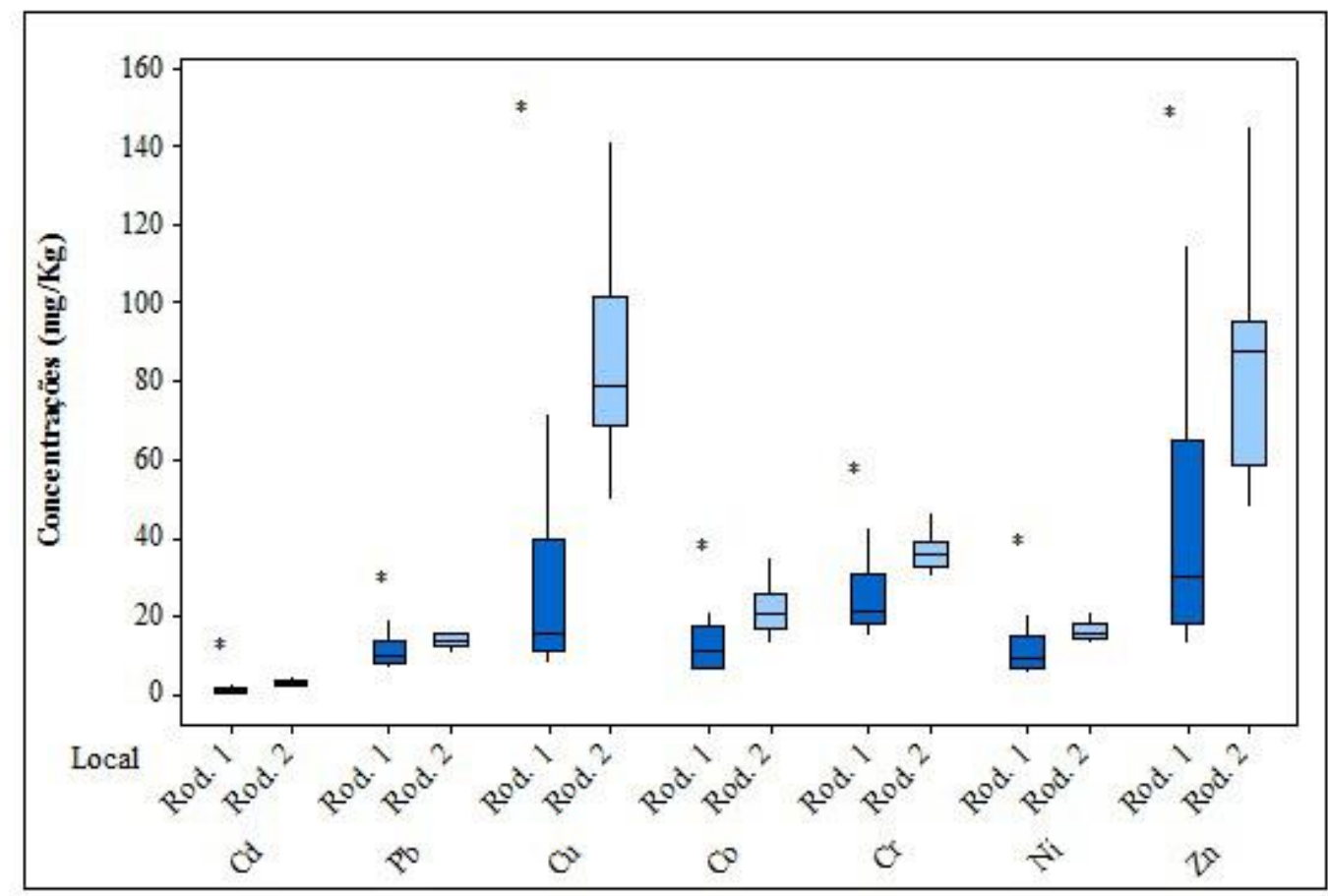

Figura 5 - Relação entre as concentrações de cada metal em sedimentos nas rodovias Domingos Sartori (Rod. 1) e Marechal Rondon (Rod. 2) *(Teste de Mann Whitney p<0,05).

Para efeito de comparação entre os teores de metais obtidos nos solos (Belluta et al., 2018) e sedimentos, as figuras 6 e 7 apresentam a variação e a dispersão das concentrações dos metais em estudo no $\mathrm{P}_{1}$ e $\mathrm{P}_{2}$, respectivamente.

As concentrações dos metais $\mathrm{Pb}, \mathrm{Cu}$ e $\mathrm{Zn}$ e o IMO em solos no $\mathrm{P}_{1}$ estão altas em relação à concentração dos demais metais em sedimentos (Figura 6).

As diferenças de teores de metais entre solos e sedimentos podem ter ocorrido devido ao intenso arraste ou à maior mobilidade desses contaminantes para a calha do córrego. O provável incremento dos metais nos sedimentos pode ter ocorrido em virtude de dois tributários receptores de contaminação difusa oriundos do condomínio Parque das Cascatas, que desembocam nos subpontos $\mathrm{P}_{1.5}, \mathrm{P}_{1.6}$ e $\mathrm{P}_{1.7}$ (Figura 1), observado também no local correspondente ao mapa de relevo (Figura 3). Nos estudos realizados por Belluta et al. (2018), além da influência da contaminação de origem difusa do Parque das Cascatas, outro possível foco de contaminação seria o estacionamento desativado de vagões e trens da antiga linha férrea na linha do divisor de águas da sub-bacia. As medianas dos gráficos de caixas do material em análise (sedimento e solo) estão próximas e, por isso, não variaram estatisticamente, com exceção do Cd (outliers).

$\mathrm{Na}$ figura 7, a mediana do gráfico de caixas indica a maior concentração dos metais $\mathrm{Pb}$ e $\mathrm{Cr}$ e o IMO encontrados nos solos do $\mathrm{P}_{2}$, possivelmente provocados pela baixa mobilidade desses elementos. Os altos teores do $\mathrm{Cd}, \mathrm{Cu}, \mathrm{Co}$, $\mathrm{Ni}$ e $\mathrm{Zn}$ em sedimentos podem ter sido influenciados pela maior mobilidade nos períodos chuvosos. Assim, as prováveis fontes de 
contaminação difusa que podem estar também agregando metais nos sedimentos no $\mathrm{P}_{2}$ são o condomínio Spazio Verde - $\left(\mathrm{P}_{2.10}\right)$ e o bairro Recanto Azul - $\left(\mathrm{P}_{2.14}\right)$, devido às suas localizações observados na Figura 1 e local correspondente na figura 3 . O gráfico de caixas indica que somente os metais $\mathrm{Cd}, \mathrm{Pb}$ e $\mathrm{Co}$ variaram estatisticamente (outliers). Os demais metais apresentaram proximidade das medianas no conjunto das suas concentrações entre solo e sedimento.

Na figura 8 , observa-se que a ordem crescente de concentração da maioria dos metais, principalmente do $\mathrm{Cu}$, do $\mathrm{Zn}$ e do $\mathrm{Cr}$, nos subpontos $\mathrm{P}_{1}$ e $\mathrm{P}_{2}$ tendem no sentido montante $\left(\mathrm{P}_{1.1}\right.$ ao $\mathrm{P}_{1.3}$ e $\mathrm{P}_{2.8}$ ao $\left.\mathrm{P}_{2.10}\right)$ e jusante $\left(\mathrm{P}_{1.4}\right.$ ao $\mathrm{P}_{1.7} \mathrm{e}$ $\mathrm{P}_{2.11}$ ao $\left.\mathrm{P}_{2.14}\right)$, cujos valores são diretamente proporcionais à distância da rodovia, ou seja, o inverso da ordem dos teores encontrados em solos por Belluta et al. (2018).

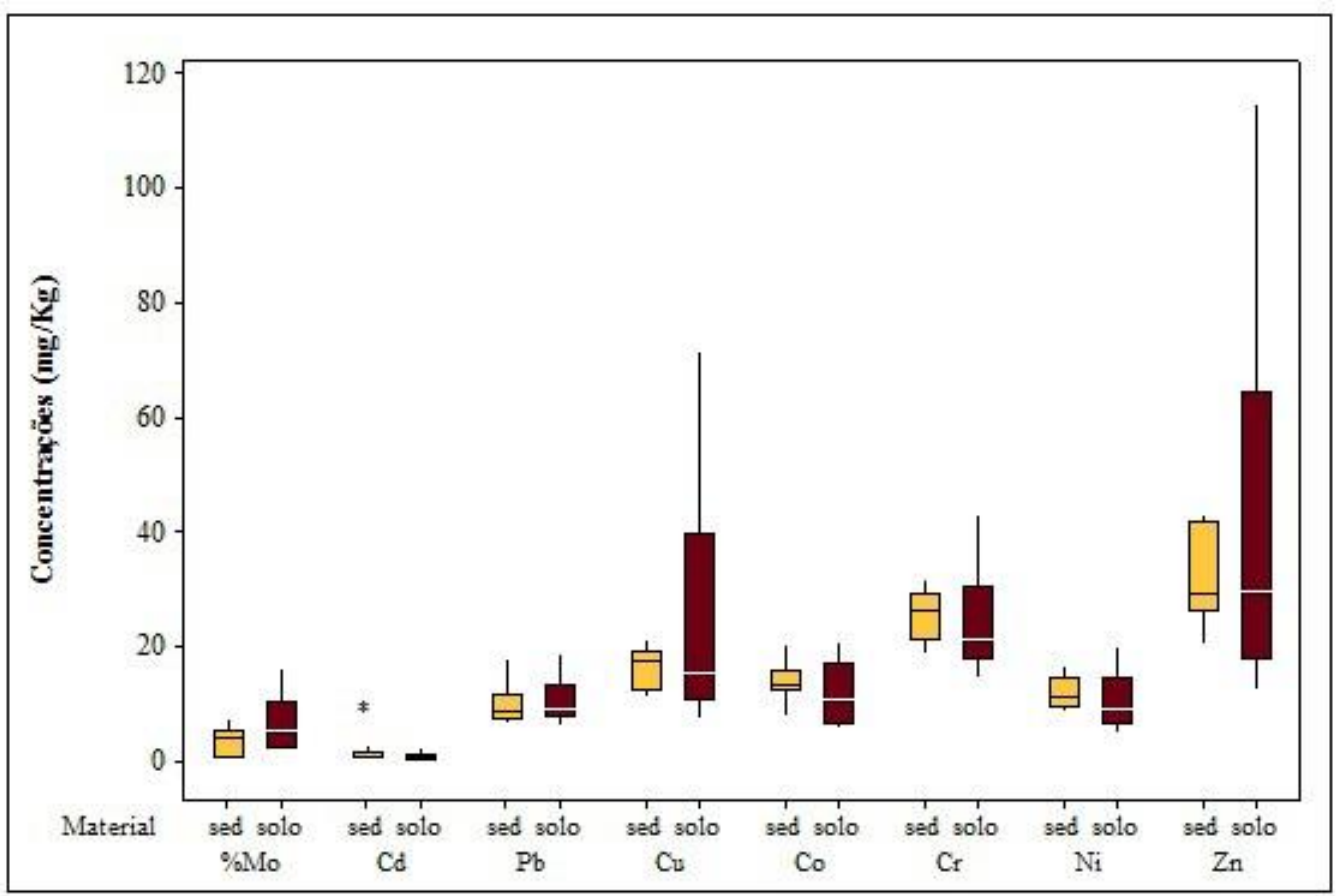

Figura 6 - Relação entre as concentrações de cada metal nas variáveis solo (Belluta et al. 2018) e sedimento no $\mathrm{P}_{1}$ $*(\mathrm{p}<0,05)$.

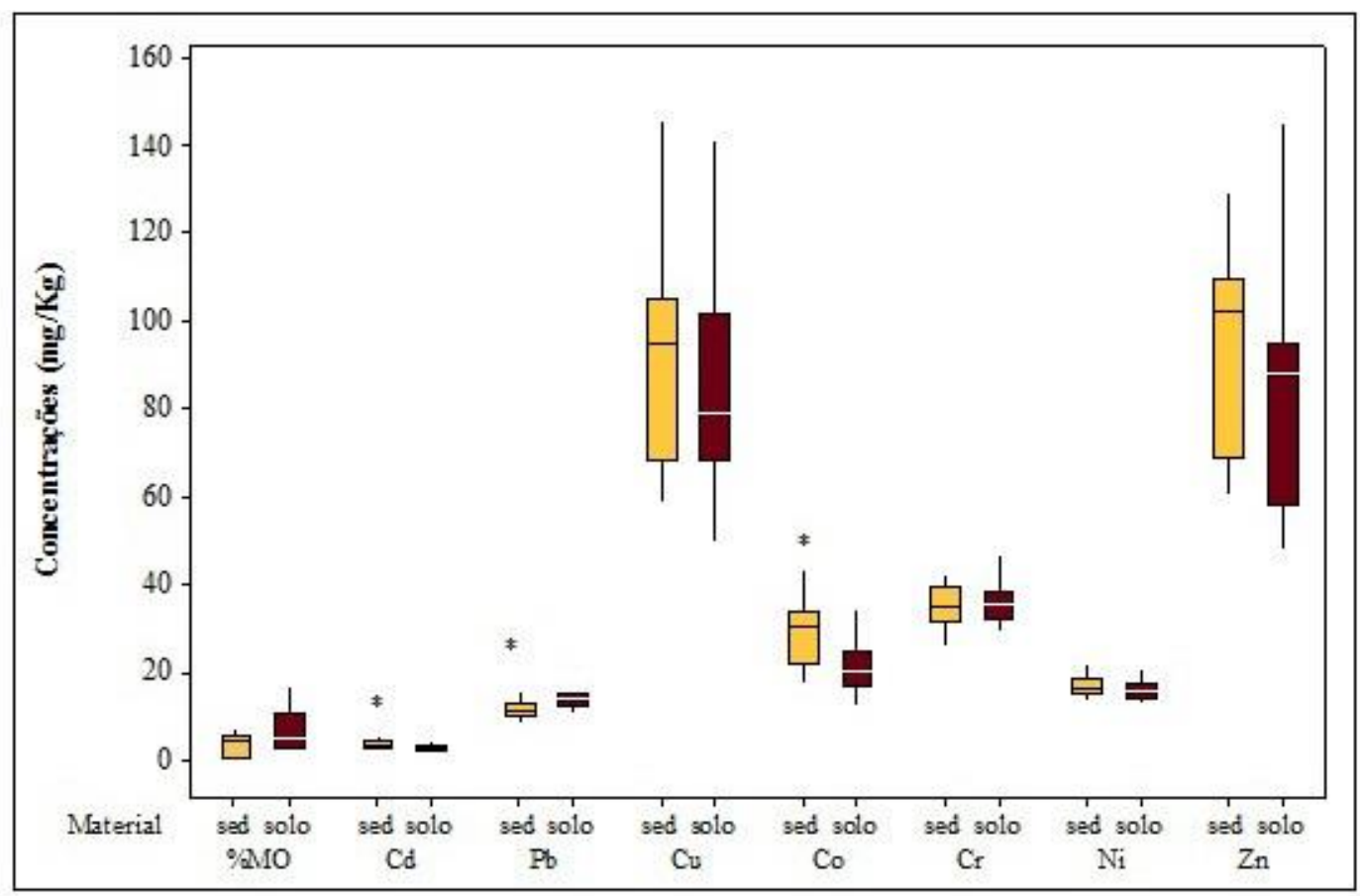

Figura 7 - Relação entre as concentrações de cada metal em sedimentos nas variáveis solo (Belluta et al. 2018) e sedimento no $\mathrm{P}_{2} *(\mathrm{p}<0,05)$. 
Entre as concentrações dos metais apresentados, os valores estão baixos nos subpontos $\mathrm{P}_{1.1}, \mathrm{P}_{1.4}, \mathrm{P}_{2.8}, \mathrm{P}_{2.11}$ e $\mathrm{P}_{2.12}$, apesar de estarem mais próximos das rodovias. Observa-se na Figura 8 que no $\mathrm{P}_{1}$, os subpontos $\mathrm{P}_{1.5}, \mathrm{P}_{1.6} \mathrm{e}$ $\mathrm{P}_{1.7}$ apresentaram incremento do $\mathrm{Zn}$, possivelmente devido à desembocadura de dois tributários localizados a cada lado do condomínio Parque das Cascatas (Figura 1e 3), já observado na Figura 6.

No $\mathrm{P}_{2}$, as concentrações dos elementos $\mathrm{Cu}$ e $\mathrm{Zn}$ apresentam altos teores nos subpontos mais distantes das rodovias, e no $\mathrm{P}_{2.8}$, no $\mathrm{P}_{2.9}$ e no $\mathrm{P}_{2.10}$ esses contaminantes podem ter sido carreados a partir do condomínio Spazio Verde, assim como no $\mathrm{P}_{2.14}$, do bairro Recanto Azul (Figura 1), como já foi também observado anteriormente (Figura 6). Portanto, esses dados condizem com a hipótese de contaminação por metais oriundos das rodovias, no qual são considerados primários e com focos secundários de contaminação (área urbana), que serão avaliados individualmente em um estudo posterior. Resultados similares foram encontrados em estudo anterior realizado por Belluta et al. (2018).

A figura 8 apresenta ainda a interação dos metais analisados com a matéria orgânica (MO) em cada subponto. Os teores dos metais analisados no $\mathrm{P}_{\mathrm{T}}$ foram inferiores aos encontrados nos demais subpontos, o que indica não haver relação direta com o IMO $(7,5 \%)$ e a contaminação de origem antrópica.

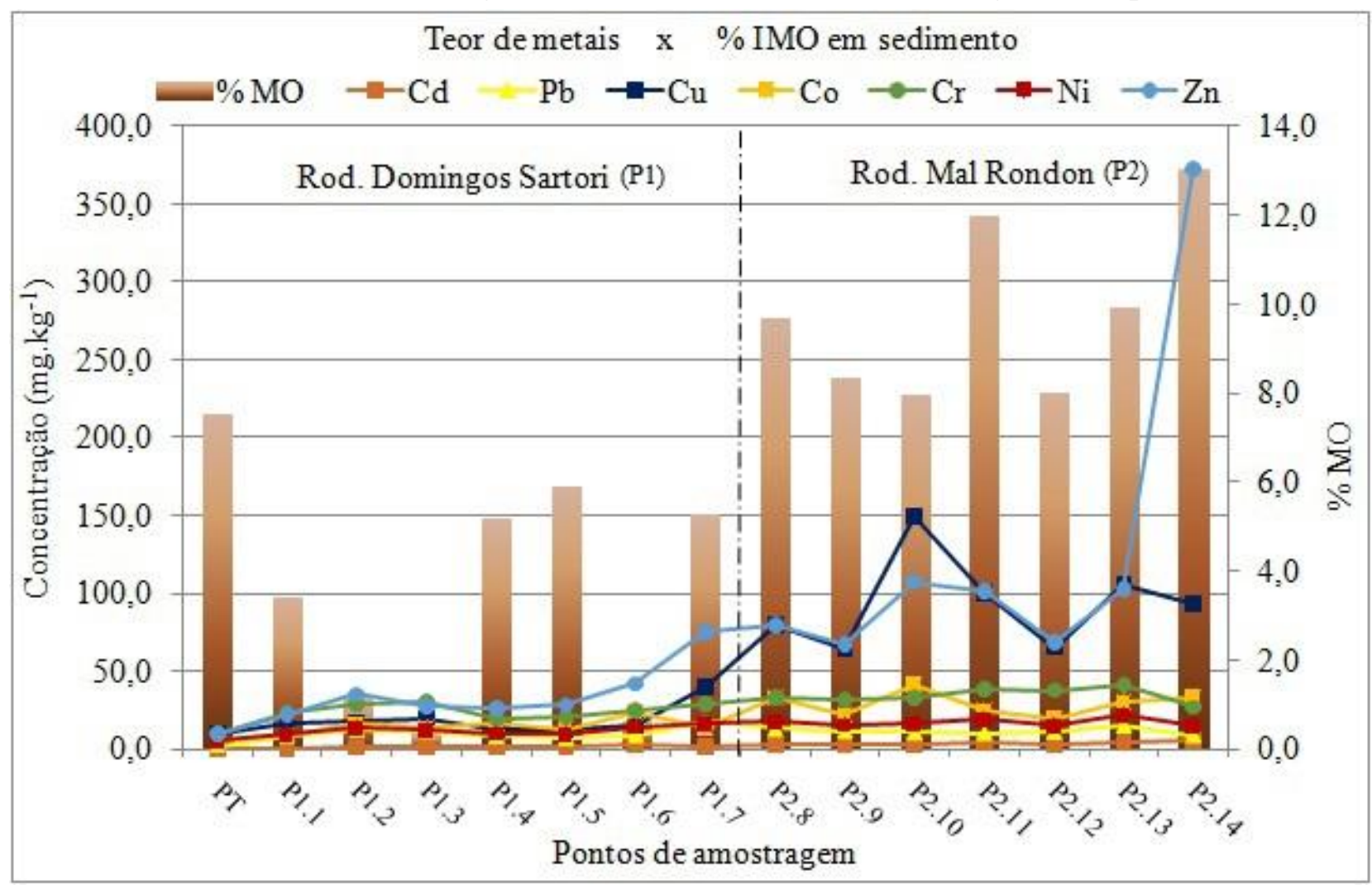

Figura 8 - Variação das concentrações de sedimentos nos pontos de amostragem $\left(\mathrm{P}_{1}\right.$ e $\left.\mathrm{P}_{2}\right)$. À direita, escala do IMO (\%) e, à esquerda, das espécies metálicas obtida em mg.kg-1.

Diferente do $\mathrm{P}_{\mathrm{T}}$, os subpontos do $\mathrm{P}_{2}$ apresentaram maior IMO $(7,9 \%$ a $13,0 \%)$ em relação aos subpontos do $\mathrm{P}_{1}$, que variou de $0,4 \%$ a $5,9 \%$. No $\mathrm{P}_{1}$, o $\mathrm{P}_{1.5}$ apresenta-se com IMO maior $(5,9 \%)$ e segue em ordem decrescente de concentração: $\mathrm{P}_{1.7}(5,3 \%), \mathrm{P}_{1.4}(5,2 \%)$ e $\mathrm{P}_{1.1}$ $(3,4 \%)$, mantendo relação direta com a $\mathrm{MO}$ principalmente para os metais $\mathrm{Zn}, \mathrm{Cu}$ e $\mathrm{Cr}$. Os outros subpontos apresentam baixo IMO. No $\mathrm{P}_{2}$, os mesmos metais seguem também essa ordem, iniciando no $\mathrm{P}_{2.14}$ com o maior $\operatorname{IMO}(13,0 \%)$, seguido de $\mathrm{P}_{2.11}(12,0 \%), \mathrm{P}_{2.13}(9,9 \%), \mathrm{P}_{2.8}(9,7 \%)$ até $\mathrm{P}_{2.10}(7,9 \%)$. Os demais metais nas duas rodovias não apresentaram relação com a MO. Neste estudo, a relação entre o IMO e a concentração dos metais esteve na ordem decrescente para todas as espécies metálicas encontradas: $\mathrm{Zn}>\mathrm{Cu}>\mathrm{Cr}>\mathrm{Co}>\mathrm{Ni}>\mathrm{Pb}>\mathrm{Cd}$, e os resultados são similares aos obtidos no solo na sub-bacia do Córrego da Cascata (Belluta et al., 2018).

A fração granulométrica utilizada tanto para solos como para sedimentos foi de $75 \mu \mathrm{m}$, e, de acordo com Minello et al. (2009) e Martinez et 
al. (2010), a análise de metais em sedimentos nessa dimensão é um sensível indicador de poluição por espécies metálicas, que pode ser eletricamente ativa, além de possuir uma grande superfície específica para adsorver os metais. Para os autores, a correlação obtida foi direta entre a $\mathrm{MO}$ e a granulometria dos sedimentos (65 $\mu \mathrm{m})$, independentemente da origem da amostra.

A maior ou menor disponibilidade de espécies metálicas está vinculada à quantidade de MO nos horizontes superficiais do solo, cujo produto de degradação torna os metais mais biodisponíveis (Vinhal-Freitas et al., 2010; Beló et al., 2010). Em estudos de sedimentos na Baía de Guanabara (RJ), Pereira et al. (2007) encontraram altos níveis de MO e metais e indicaram também que as áreas urbanas e de rodovias foram as fontes potenciais de poluição costeira.

Nos estudos de Costa \& Espíndula (2002), os resultados dos metais em sedimentos estão próximos aos obtidos no presente estudo. Os rios afluentes localizados na região da Bacia Hidrográfica do Médio Tietê Superior indicaram estado de degradação ambiental também pelos metais $\mathrm{Zn}, \mathrm{Cu}$ e $\mathrm{Cr}$, com teores de $\mathrm{MO}$ inferiores a $13,1 \%$ nos sedimentos nos rios Piracicaba, Tietê, Capivari e no Ribeirão Lavapés, que é receptor primário do Córrego da Cascata e efluente doméstico tratado do município de Botucatu. Poleto \& Merten (2008) encontraram concentrações de $\mathrm{Ni}$ acima dos valores background em até três vezes e alta afinidade com o IMO, mas revelaram ser menos disponível em relação ao $\mathrm{Zn}$. Pierangeli et al. (2005) revelaram que a MO é um bom carreador de substâncias e não apresentou correlação com o $\mathrm{Cd}$ e com as outras espécies metálicas. Segundo os autores, essas interações entre os constituintes do solo e os sedimentos ocorrem normalmente devido ao descontrole do $\mathrm{pH}$ na presença da $\mathrm{MO}$, além de apresentar diversos grupamentos funcionais reativos (aminas, carboxilas, fenólicos, carbonilas, alcoólicos e sulfidrilas), responsáveis pela retenção e mobilidade dos metais.

Com a finalidade de identificar os subpontos de amostragem que se afastaram das condições naturais provocadas pela interferência das áreas limítrofes da sub-bacia, rodovias e bairros adjacentes, a Tabela 1 apresenta os Fatores de Contaminação (FC), relacionando a concentração de cada metal e o VMM no subponto, obtidos através do método de Hakanson (1980), modificado por Beló et al. (2010). A análise de cada metal constante na tabela revelará as prováveis origens de contaminação de acordo com os subpontos.

De acordo com Kabata-Pendias (2010), os VMM utilizados para a determinação do FC foram: $\mathrm{Cd}=0,3 \mathrm{mg} \cdot \mathrm{L}^{-1}, \mathrm{~Pb}=19,0 \mathrm{mg} \cdot \mathrm{L}^{-1}, \mathrm{Cu}=33,0$ mg. $\mathrm{L}^{-1}, \mathrm{Cr}=90,0 \mathrm{mg} . \mathrm{L}^{-1}, \mathrm{Ni}=52,0 \mathrm{mg} . \mathrm{L}^{-1}, \mathrm{Zn}=95$ $\mathrm{mg} \cdot \mathrm{L}^{-1}$. Somente o Co não consta na tabela 1 , devido à ausência de VMM.

Tabela 1 - Fator de Contaminação (FC) nos pontos de amostragem nas rodovias

\begin{tabular}{|c|c|c|c|c|c|c|c|c|c|c|c|c|c|}
\hline \multicolumn{7}{|c|}{ FC Rod. Domingos Sartori } & \multicolumn{7}{|c|}{ FC Rod. Mal Rondon } \\
\hline & $\mathrm{Cd}$ & $\mathrm{Pb}$ & $\mathrm{Cu}$ & $\mathrm{Cr}$ & $\mathrm{Ni}$ & $\mathrm{Zn}$ & & $\mathrm{Cd}$ & $\mathrm{Pb}$ & $\mathrm{Cu}$ & $\mathrm{Cr}$ & $\mathrm{Ni}$ & $\mathrm{Zn}$ \\
\hline $\mathrm{P}_{\mathrm{T}}$ & 0,4 & 0,5 & 0,3 & 0,1 & 0,1 & 0,2 & $\mathrm{P}_{\mathrm{T}}$ & 0,4 & 0,5 & 0,3 & 0,1 & 0,1 & 0,2 \\
\hline$P_{1.1}$ & 2,5 & 0,4 & 0,5 & 0,3 & 0,2 & 0,2 & $P_{28}$ & 10,0 & 0,7 & 2,4 & 0,4 & 0,3 & 0,8 \\
\hline $\mathrm{P}_{12}$ & 3,1 & 0,6 & 0,5 & 0,3 & 0,3 & 0 , & $\mathrm{P}_{29}$ & 8,7 & 0,6 & 2,0 & 0,4 & 0,2 & 0,7 \\
\hline $\mathrm{P}_{13}$ & 5,7 & 0,6 & 0,6 & 0,3 & 0,2 & 0,3 & $\mathrm{P}_{210}$ & 9,3 & 0,5 & 4,5 & 0,4 & 0,3 & 1,1 \\
\hline $\mathrm{P}_{14}$ & 3,6 & 0,4 & 0,4 & 0,2 & 0,2 & 0,3 & $P_{211}$ & 15,3 & 0,5 & 3,0 & 0,4 & 0,4 & 1,1 \\
\hline$P_{15}$ & 6,0 & 0,4 & 0,4 & 0,2 & 0,2 & 0,3 & $P_{212}$ & 9,0 & 0,6 & 2,0 & 0,4 & 0,3 & 0,7 \\
\hline$P_{1.6}$ & 8,9 & 0,8 & 0,5 & 0,3 & 0,3 & 0,4 & $P_{213}$ & 13,4 & 0,8 & 3,2 & 0,5 & 0,4 & 1,2 \\
\hline$P_{1.7}$ & 5,2 & 0,9 & 1,2 & 0,3 & 0,3 & 0,8 & 2.14 & 18,7 & 0,5 & 2,8 & 0,3 & 0,3 & 3,9 \\
\hline
\end{tabular}

Os valores de FC para o $\mathrm{P}_{\mathrm{T}}$ foi inferior a 1 para todos os metais, caracterizando ambiente de "Baixa" contaminação. O Cd apresentou contaminação "Moderada" no $\mathrm{P}_{1.1}$, "Considerável" (3 a 6) nos subpontos $\mathrm{P}_{1.2}, \mathrm{P}_{1.3}$, P1.4 e P1.5 e "Alta" no $\mathrm{P}_{1.6}(>6,0)$. O Cd foi o único elemento que indicou contaminação secundária oriunda da desembocadura do tributário, localizado a montante da rodovia e do condomínio Parque das Cascatas, nos subpontos $\mathrm{P}_{1.5}$ e $\mathrm{P}_{1.6}$ (Figura 2), como já foi observado em análises anteriores. $\mathrm{O} \mathrm{Cu}$ apresentou $\mathrm{FC}$ "Moderado" no $\mathrm{P}_{1.7}(1,2)$, também indicativo de contaminação secundária na desembocadura localizada a jusante do condomínio Parque das Cascata (Figura 2). Já para $\mathrm{Pb}(0,9)$ e $\mathrm{Zn}(0,8)$, o 
resultado do estudo indicou FC "Baixo" e próximo de 1, assim como nas demais variáveis.

Os mesmos elementos apresentaram maior FC no $\mathrm{P}_{2}$, onde foi registrado índice de concentração superior a 1 para os metais $\mathrm{Cd}, \mathrm{Cu}$ e $\mathrm{Zn}$ em quase todos os subpontos. O Cd apresentou elevada concentração no subponto $\mathrm{P}_{2.10}$ e FC superior a 6 , índice "Alto" de contaminação, confirmando a influência de contaminação secundárias pelo condomínio Spazio Verde já observada. A contaminação por $\mathrm{Cu}$ e $\mathrm{Zn}$ ficou na faixa de "Considerável" (3-6) nos subpontos $\mathrm{P}_{2.10}, \mathrm{P}_{2.11}$, $\mathrm{P}_{2.13}$ e $\mathrm{P}_{2.14}$ e "Moderado" para os demais subpontos, o que determina a contaminação por influência dos condomínios Spazio Verde e bairro Recanto Azul. Nos demais subpontos, esses metais apresentaram índices de concentração próximos de 1 . Semelhante a esses resultados, Beló et al. (2010) apresentaram também incremento de $\mathrm{Cu}$ e $\mathrm{Zn}$ acima do background local, indicando FC "Moderado" e com boa mobilidade no sistema aquático.

Ao se comparar os subpontos mais distantes das rodovias, o $\mathrm{P}_{1.9}$ e $\mathrm{P}_{2.18}$ das análises de solos (Belluta et al., 2018), que correspondem aos mesmos subpontos $\mathrm{P}_{1.7}$ e $\mathrm{P}_{2.14}$ das análises de sedimentos do presente estudo, constata-se que os teores são maiores para os metais $\mathrm{Cd}, \mathrm{Cu}$ e $\mathrm{Zn}$ em relação aos outros subpontos, observados através dos valores de FC (Tabela 1). De acordo com os mesmos autores, o subponto $\mathrm{P}_{1.9}$ das análises dos solos corresponde ao $\mathrm{P}_{1.7}$ dos sedimentos, que apresentou FC acima de 1 para $\mathrm{Cu}$ e acima de 2,5 para $\mathrm{Cd}$, cuja origem da contaminação difusa está no condomínio Parque das Cascatas (Figura 1 e 2). Já o $\mathrm{P}_{2.18}$ demarcado para análise de solo e o $\mathrm{P}_{2.14}$ para sedimentos apresentaram elevado FC: 18,7 para Cd, 2,8 para $\mathrm{Cu}$ e 3,9 para $\mathrm{Zn}$, cuja contaminação foi de origem difusa oriunda do bairro Recanto Azul. Estes subpontos apresentaram resultados próximos aos obtidos nos solos por Belluta et al. (2018).

A toxicidade de cada metal varia de acordo com o elemento e, segundo Branco (1978), os efeitos tóxicos dos metais causados sobre a flora e a fauna aquáticas (especialmente sobre peixes) são geralmente resultantes de várias atividades humanas. Experiências realizadas em organismos aquáticos mostraram a seguinte ordem decrescente de toxicidade para alguns metais: $\mathrm{Cu}>\mathrm{Cd}>\mathrm{Ni}>\mathrm{Pb}>\mathrm{Cr}$ (Madoni \& Romeo, 2006). De acordo com Baird \& Cann (2011), a bioacumulação desses poluentes é um dos efeitos mais sérios da contaminação ambiental e possibilita o transporte dos contaminantes através dos diversos níveis tróficos da cadeia alimentar. Por outro lado, a biomagnificação desses elementos acontece quando as concentrações aumentam progressivamente ao longo da cadeia alimentar ecológica.

Entre as espécies químicas encontradas no presente estudo, o $\mathrm{Cu}$, o Co e o $\mathrm{Zn}$ são essenciais aos seres vivos e têm importante papel no metabolismo dos organismos aquáticos. Mesmo assim, em grandes concentrações, elas podem apresentar toxicidade. Os elementos $\mathrm{Cd}, \mathrm{Pb}, \mathrm{Cr}$ e Ni não têm função biológica conhecida e são geralmente tóxicos em uma grande variedade de organismos, incluindo o homem (Esteves \& Guariento, 2011).

Considerando a toxicidade de cada metal, foi realizada a avaliação das espécies metálicas encontradas em relação aos efeitos adversos sobre a biota, de acordo com os parâmetros estabelecidos pelo CONAMA (2004) e por Buchiman (2008).

Assim, o $\mathrm{Cd}$ possui uma grande mobilidade em ambientes aquáticos, é biopersistente e, uma vez absorvido por um organismo, permanece nele por muitos anos (ao longo de décadas nos seres humanos), embora eventualmente seja excretado (Hann \& Jensen, 1974, Lenntech, 2017). De acordo com Kabata-Pendias (2010), esse metal é considerado o mais ecotóxico e com efeitos adversos sobre todos os processos biológicos nos seres humanos, nos animais e nas plantas. As altas concentrações de $\mathrm{Cd}$ em solos e sedimentos superficiais refletem a sua bioacumulação bem como suas fontes antropogênicas.

A Figura 9A revela que o metal $\mathrm{Cd}$ no $\mathrm{P}_{1}$ apresentou concentração próxima da qual raramente são esperados efeitos adversos para os organismos (TEL=0,6 mg.kg-1) nos subpontos $\mathrm{P}_{1.1}, \mathrm{P}_{1.2}$ e $\mathrm{P}_{1.4}$, mas com tendência aos valores esperados para efeitos adversos (PEL $=3,5 \mathrm{mg} . \mathrm{kg}^{-}$ $\left.{ }^{1}\right)$ nos subpontos $\mathrm{P}_{1.3}, \mathrm{P}_{1,5}, \mathrm{P}_{1.6}$ e $\mathrm{P}_{1.7}$. Entre os valores de TEL e PEL, existe uma zona de transição na qual os efeitos biológicos de toxicidade são incertos. No $\mathrm{P}_{2}$, as concentrações foram maiores, tendendo ao PEL para todos os subpontos, com destaque para o $\mathrm{P}_{2.11}$ e o $\mathrm{P}_{2.14}$, que apresentaram valores próximos ao nível de efeitos adversos severos sobre a biota (SEL), que é de 10,0 mg. $\mathrm{kg}^{-1}$ (Buchiman, 2008). Entre os 
metais analisados na região da Bacia Hidrográfica do Médio Tietê Superior e na confluência dos rios Tietê e Piracicaba (Bramorski, 2004), as concentrações médias de Cd nos sedimentos do Tietê $(6,04$ a $7,37 \mathrm{mg} . \mathrm{kg}$ $\left.{ }^{1}\right)$ variaram de 20 a 30 vezes mais elevados em relação aos do Piracicaba, considerado altamente poluído. Ao considerar o $\mathrm{Cd}$ como valor de referência de efeitos adversos sobre a biota, está em pelo menos 3 vezes maior o valor do PEL. Neste estudo, os valores testemunhos de todos os metais encontrados nas nascentes dos tributários do Tietê apresentaram teores baixos em relação aos resultados $\left(0,12\right.$ a $\left.0,14 \mathrm{mg} \cdot \mathrm{kg}^{-1}\right)$.

Quanto ao metal $\mathrm{Cu}$, seus efeitos gerais sobre a população dos rios são semelhantes aos produzidos pelo $\mathrm{Pb}$. Assim, os peixes são mais sensíveis e morrem pela contaminação desses elementos na coluna d'água. Com o aumento da concentração do metal, são atingidos moluscos, crustáceos, oligoquetos, sanguessugas e certos tipos de insetos. A vegetação fica reduzida a certos gêneros de algas, musgos e plantas aquáticas (Branco, 1978).

Nas duas rodovias que passam pela região estudada no município de Botucatu (SP), o elemento $\mathrm{Pb}$ (Figura 9B) está abaixo do TEL (35,0 mg. $\left.\mathrm{kg}^{-1}\right)$, não indicando a contaminação do córrego por esse metal. $\mathrm{O}$ mesmo ocorre para o metal $\mathrm{Cu}$ no $\mathrm{P}_{1}$ (Figura 9C), mas no $\mathrm{P}_{2}$, o valor do $\mathrm{P}_{2.10}$ está mais próximo $\left(149,1 \mathrm{mg} \cdot \mathrm{kg}^{-1}\right)$ do valor do PEL, que é de $197 \mathrm{mg} \cdot \mathrm{kg}^{-1}$. Minello et al. (2009) analisaram metais em sedimentos no reservatório do Rio Paraná, em Ilha Solteira (SP), onde o $\mathrm{Cu}$ esteve próximo ao limite TEL (35,7 mg. $\mathrm{kg}^{-1}$ ) em duas amostragens e excedeu pelo menos 1,6 vezes o limite PEL em um ponto amostral, já representando risco à biota. Já $\mathrm{o} \mathrm{Pb}$ chegou a $288,0 \mathrm{mg} \cdot \mathrm{kg}^{-1}$ (1,1 vez superior ao SEL), no estudo de Bramorski (2004).

Nos estudos de Belluta et al. (2008 e 2014), foram encontradas, em sub-bacia adjacente à do Córrego da Cascata, altas concentrações de $\mathrm{Cu}$ e $\mathrm{Pb}$ em sedimentos em áreas de influência agrícola e da Rodovia Marechal Rondon.

Os teores de $\mathrm{Cu}$ variaram de 17,5 a 770 mg.kg${ }^{1} \mathrm{e}$, com base nos mesmos valores de referência, alcançaram 4 vezes o PEL e 7 vezes o SEL (110,0 mg. $\left.\mathrm{kg}^{-1}\right)$ e o $\mathrm{Pb}$ foi de até $3.250 \mathrm{mg} \cdot \mathrm{kg}^{-1}$ com 13 vezes o SEL ( $250 \mathrm{mg} \cdot \mathrm{kg}^{-1}$ ) e próximo de 36 vezes o TEL (91,3 mg. $\mathrm{kg}^{-1}$ ), inferindo alto potencial de efeitos severos à biota.

Nos estudos de Costa \& Espíndula (2002), foram encontrados altos níveis de $\mathrm{Cu}$ no ambiente, causando disfunção nos processos fisiológicos essenciais à sobrevivência de peixes e colocando em risco a biodiversidade. $\mathrm{O}$ metal $\mathrm{Cu}$ apresentou baixa concentração, com 18,0 mg.kg ${ }^{-1}$, inferior ao TEL (Bramorski, 2004).

No ambiente aquático, a concentração do Co é muito baixa e pode agir como um nutriente limitador para o fitoplâncton marinho. É tóxico para plantas e mamíferos somente se em concentrações superiores a 1,0 mg. $\mathrm{L}^{-1}$ quando dissolvido na água (Hann \& Jensen, 1974, Lenntech, 2017).

Para o elemento Co foi encontrado somente o TEL (10,0 mg. $\mathrm{kg}^{-1}$ ) como valor de referência (Figura 9D). Assim, o $\mathrm{P}_{1.1}$ está abaixo do limite mínimo (TEL), e os demais pontos nas duas rodovias estão bem acima.

$\mathrm{O} \mathrm{Cr}$ acumula-se em organismos aquáticos, tornando perigosa a ingestão de peixes contaminados por esse elemento. Do ponto de vista ambiental, as plantas contêm sistemas que impedem a entrada de cromo em seus tecidos, mas quando a concentração aumenta no solo, consequentemente, aumenta também no sedimento, podendo haver absorção pelas plantas.

As altas concentrações de $\mathrm{Ni}$ em solos arenosos ou sedimentos podem danificar plantas e, na água, podem reduzir a taxa de crescimento de algas e de micro-organismos que, no entanto, desenvolvem resistência ao metal depois de algum tempo. Esse elemento não se acumula em plantas e animais, portanto não sofre magnificação pela cadeia alimentar (Hann \& Jensen, 1974, Lenntech, 2017).

Nas duas rodovias investigadas, os elementos $\mathrm{Cr}$ e $\mathrm{Ni}$ (Figuras 9E e 9F) apresentam concentrações próximas do limite do TEL (37, 3 e $18,0 \mathrm{mg} \cdot \mathrm{kg}^{-1}$, respectivamente), não tendendo ao PEL, e os demais subpontos estão abaixo do limite mínimo. Belluta et al. (2008 e 2014), também encontraram altas concentrações de $\mathrm{Ni}$ em sedimentos em áreas de agricultura e próximo à Rodovia Marechal Rondon, com teor de 525 mg.kg ${ }^{-1}$, ou seja, 15 vezes o PEL e 7 vezes o SEL. $\mathrm{O}$ Cr não foi avaliado neste estudo. Bramorski (2004) encontrou variação do Ni de 21,7 a 24,9 mg.kg ${ }^{-1}$ (1,2 a 1,4 vezes maior o TEL) em alguns pontos de amostragem.

O Zn pode aumentar a acidez das águas e se acumular em peixes, podendo bioacumular-se e magnificar-se na teia alimentar. 


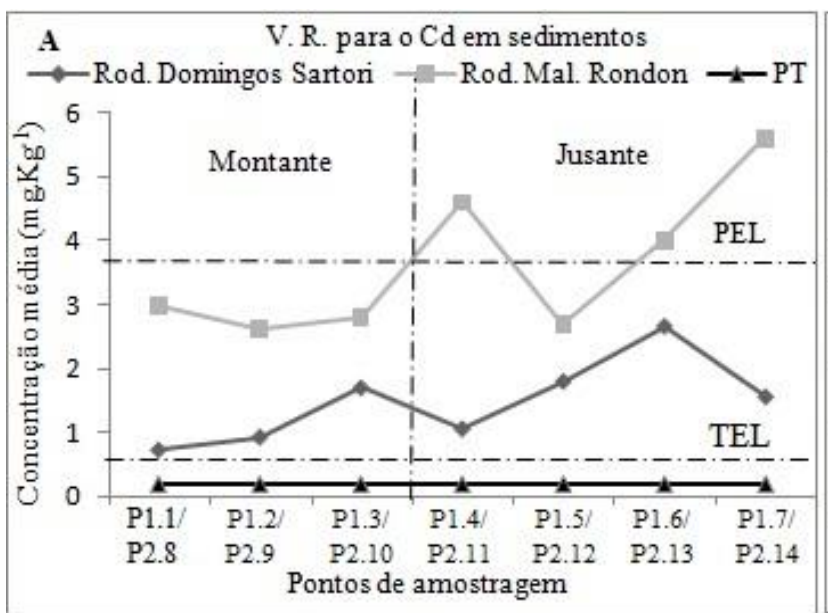

B V.R. para o $\mathrm{Pb}$ em sedimentos
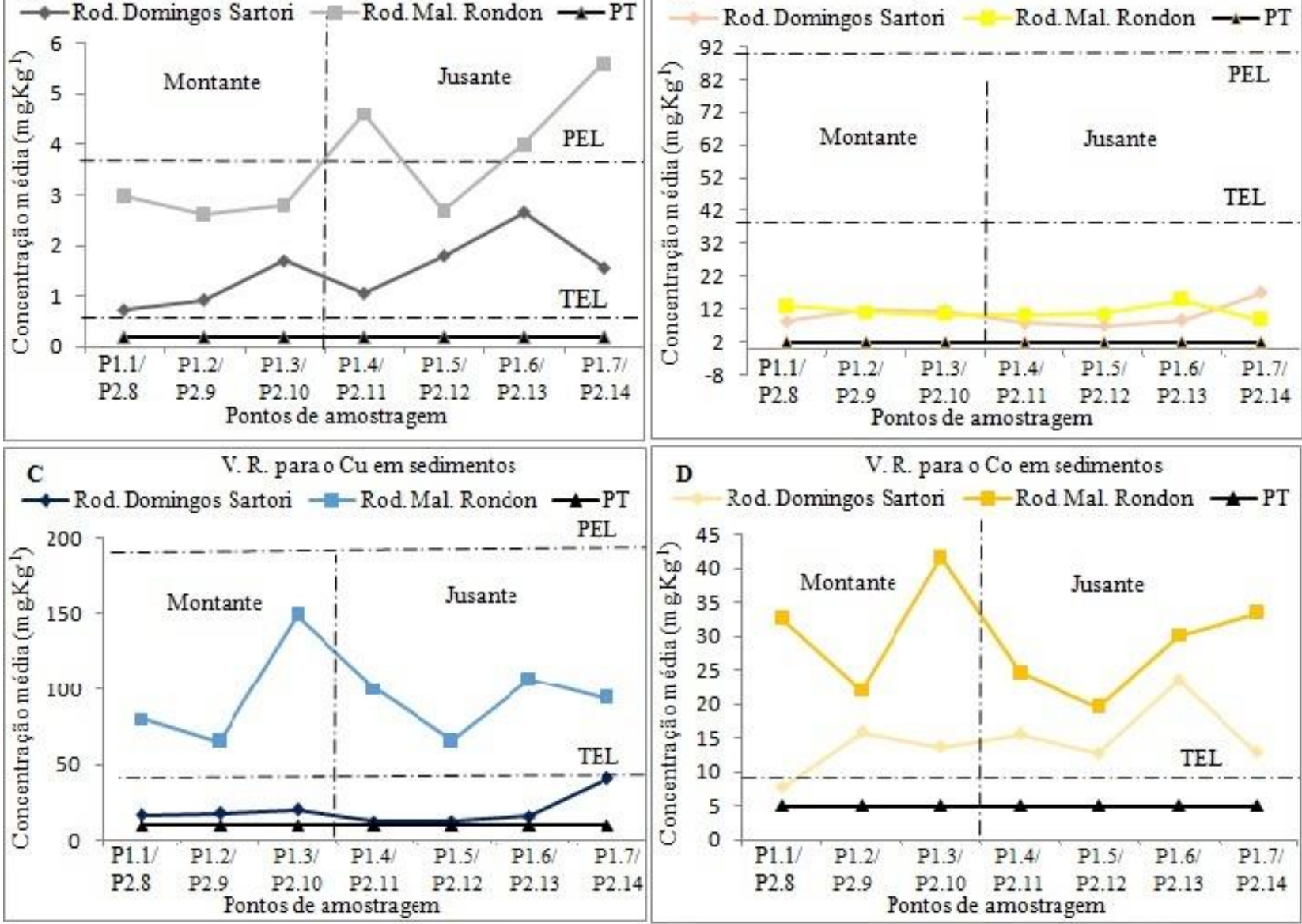

D V.R. para o Co em sedimentos

Rod. Domingos Sartori - Rod Mal. Rondon $\rightarrow-P T$
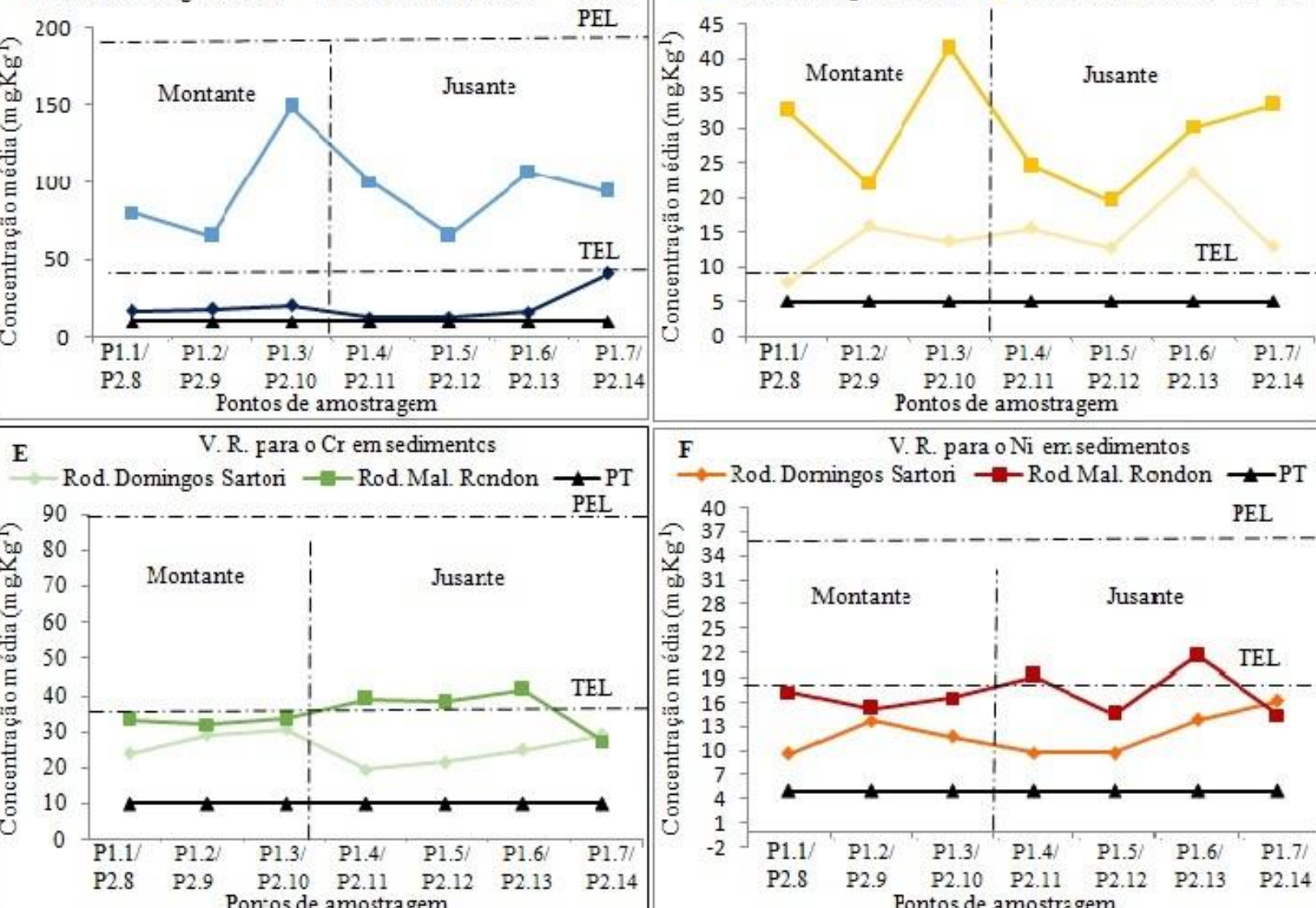

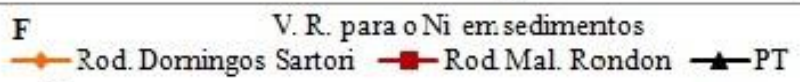
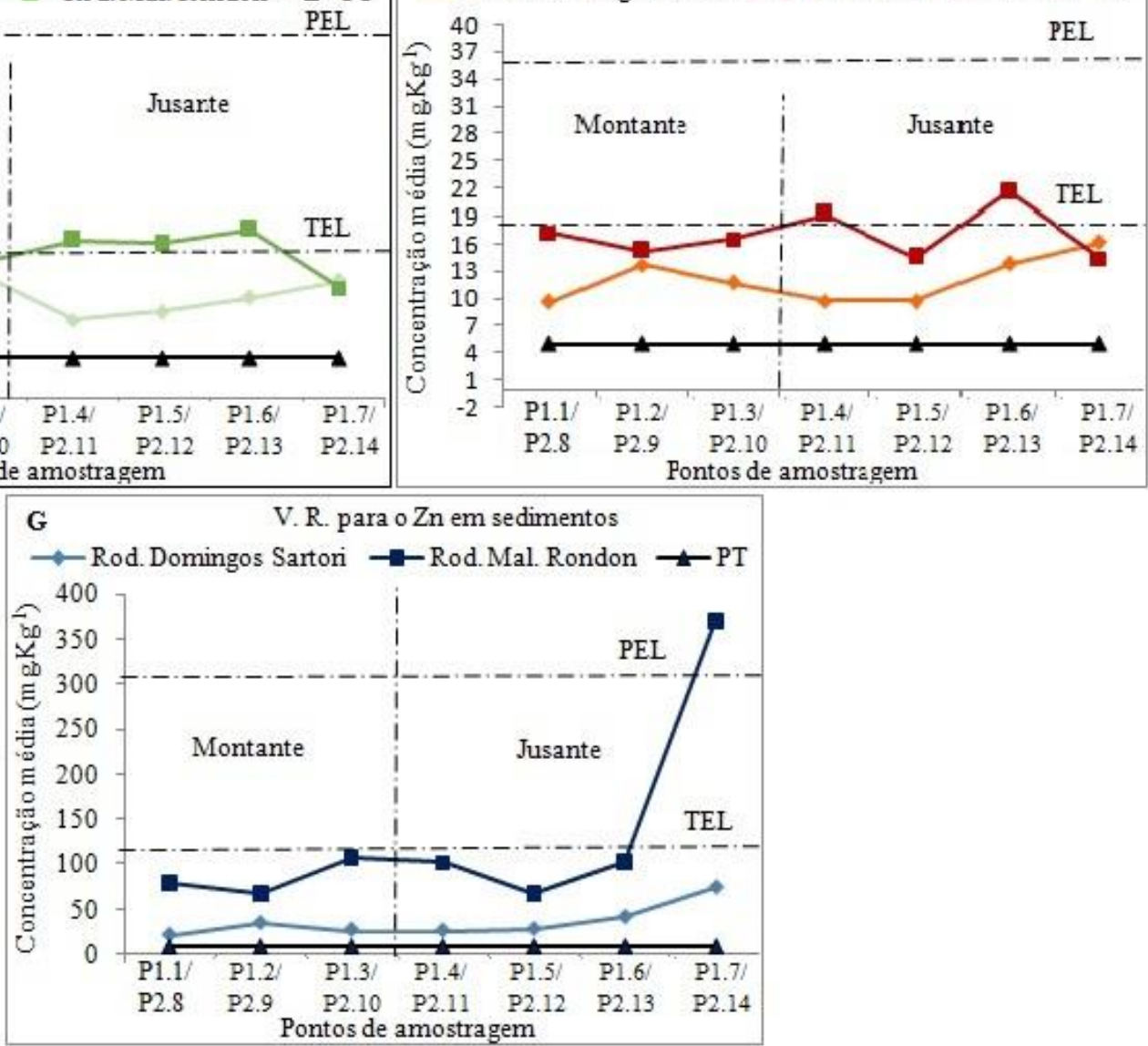

Figura 9 - Variação das concentrações de cada espécie metálica em sedimentos nos pontos de amostragem segundo VRQs TEL e PEL.

São Paulo, UNESP, Geociências, v. 39, n. 2, p. 543 - 558, 2020 
Solos contaminados em fazendas podem ser ameaça tanto para o gado quanto para as plantas. Plantas frequentemente absorvem teores maiores desse elemento do que com os quais são capazes de lidar; assim, poucas espécies sobrevivem em solos contaminados por Zn (Hann \& Jensen, 1974; Lenntech, 2017). Branco (1978) revela que os efeitos tóxicos do $\mathrm{Zn}$ sobre peixes e algas causam mortes em massa. De acordo com o autor, todos os sais de $\mathrm{Zn}$, quando em grandes concentrações, são prejudiciais por causarem elevação da pressão osmótica, ou seja, promover a plasmólise ou a turgescência celular, levando à morte dos organismos.

A figura $9 \mathrm{G}$ indica o mesmo para o $\mathrm{Zn}$, com exceção do $\mathrm{P}_{2.14}$, que está acima do PEL (315 mg. $\left.\mathrm{kg}^{-1}\right)$, mas distante do SEL, que é de 820 mg.kg-1 . O mesmo ocorreu nos estudos em solos de Belluta et al. (2008 e 2014), que registraram o valor máximo de $305 \mathrm{mg} \cdot \mathrm{kg}^{-1}$ de $\mathrm{Zn}$.

Entre os metais aqui estudados e nos solos analisados por Belluta et al. (2018), o Cd é considerado de alto risco de contaminação ambiental e o mais danoso em relação ao $\mathrm{Cu}$ e ao $\mathrm{Zn}$, o que merece maior atenção devido à sua elevada toxicidade e à sua ocorrência em todos os pontos de amostragem. Assim, a ordem de grandeza do nível natural dos metais em sedimento foi excedida em relação aos VMM, através do $\mathrm{FC}$, indicando o enriquecimento do elemento $\mathrm{Cd}$ seguido do $\mathrm{Cu}$ e do $\mathrm{Zn}$ nas áreas adjacentes às rodovias Domingos Sartori e Marechal Rondon. Contenção de carreamento de sedimento de áreas antropizadas e monitoramento sistemático das águas de escoamento das chuvas (stormwater runoff) nas rodovias e áreas urbanas devem ser realizados para mitigar a quantidade desses metais no Córrego da Cascata.

Segundo Maldonado \& Wendling (2009), entre as tecnologias de remediação de ecossistemas aquáticos contaminados mais utilizadas e estudadas na atualidade, está a biorremediação, que tanto pode ser via microorganismo quanto via vegetação. Assim, a contaminação é transferida da bacia vertente para os corpos d'água, havendo a necessidade de controlar as cargas das águas de escoamento de áreas suspeitas e no cruzamento das rodovias.

As fontes primárias e secundárias de espécies metálicas precisam ser remediadas e, em estudos futuros, serão realizadas análises de metais em plantas bioacumuladoras encontradas nos mesmos pontos amostrais e nas águas de escoamento superficial das rodovias e áreas urbanas inseridos na sub-bacia, com o objetivo de quantificar os metais para minimizar os efeitos nos organismos e na qualidade da água do Córrego da Cascata.

\section{CONCLUSÃO}

Como resultados das análises de metais em sedimentos e comparados aos dados dos solos na mesma área amostral, observou-se relações intrínsecas quanto aos índices de concentração de $\mathrm{Cd}, \mathrm{Cu}$ e $\mathrm{Zn}$ oriundos das águas de escoamento das rodovias. A influência antrópica foi constatada pelos baixos teores do $\mathrm{P}_{\mathrm{T}}$ em relação à concentração de todos os metais estudados. A rodovia Marechal Rondon apresentou maior concentração em relação à Domingos Sartori $\left(\mathrm{P}_{2}>\mathrm{P}_{1}\right)$, principalmente para $\mathrm{Cu}$ e $\mathrm{Zn}$, cujos valores estão próximos aos encontrados nos solos.

A relação entre o IMO e os metais estudados esteve na seguinte ordem decrescente de concentração: $\mathrm{Zn}>\mathrm{Cu}>\mathrm{Cr}>\mathrm{Co}>\mathrm{Ni}>\mathrm{Pb}>\mathrm{Cd}$. O FC identificou o $\mathrm{Cd}$ como o metal com maior potencial de contaminação pelo seu grau de toxicidade "Alto" em quase todos os pontos de amostragem nas duas rodovias, seguido do $\mathrm{Cu}$ e do $\mathrm{Zn}$ em pelo menos 1 subponto, na faixa de contaminação "Considerável", exceto para o $\mathrm{P}_{1}$. Os VRQs TEL e PEL do CONAMA apresentaram ordem de contaminação $\mathrm{Cd}>\mathrm{Cu}>\mathrm{Zn}$, indicando efeito de toxicidade sobre ecossistema ribeirinho, principalmente, no $\mathrm{P}_{2}$. Os teores dos demais metais são de "Baixa" contaminação. Observouse ainda que as altas concentrações dos metais obtidos nos solos refletiram diretamente no incremento dos metais nos sedimentos por arraste e deposição. Assim, a contaminação do Córrego da Cascata foi identificada pelo escoamento difuso das águas das chuvas (stormwater runoff) nas rodovias Domingos Sartori e Marechal Rondon e também nos bairros adjacentes às rodovias (condomínios Parque das Cascatas e Spazio Verde e bairro Recanto Azul), situados a partir do limite do divisor de águas da sub-bacia. Os resultados apresentados fornecem base para o monitoramento, a conservação e a proteção do Córrego da Cascata e de seus afluentes, havendo necessidade de controlar as cargas das águas de escoamento das áreas urbanas, principalmente no cruzamento das rodovias com o Córrego da Cascata. 


\section{REFERÊNCIAS}

ADRIANO, D.C. Trace elements in the terrestrial environment. Aiken, South Carolina, USA, 533 p., 1986.

ALVES, R.I.S.; TONANI, K.A.A.; NIKAIDO, N.; CARDOSO, O.O.; TREVILATO, T.M.B.; SEGURA-MUÑOZ, S.I Avaliação das concentrações de metais pesados em águas superficiais e sedimentos do córrego Monte Alegre e afluentes, Ribeirão Preto, SP, Brasil. Revista Ambiente \& Água, Taubaté SP, v. 5, n. 3, p. 122-132, 2010.

BAIRD, C. \& CANN, M. Química Ambiental. $4^{\mathrm{a}}$ ed., Porto Alegre RS: Bookman. 844 p., 2011.

BELLUTA, I.; TOFOLI, L.A.; CORRÊA, L.C.; CARVALHO, L.R.; SILVA, A.M.M. Impactos provocados por metais potencialmente tóxicos dissolvidos em águas e em sedimentos no córrego do Cintra- Botucatu SP. Revista Salusvita, Bauru SP, v. 27, n. 2, p. 239-258, 2008.

BELLUTA, I.; JESUS, S.A.; VIEIRA, M.P.; CORRÊA, N.M.; CARDOSO, L.G.; CAMPOS, S.; VALENTE, J.P.S. Assoreamento de lago na sub-bacia do córrego da Cascata em Botucatu (SP): Implicações morfométricas. Revista Caminhos de Geografia, Uberlândia, v. 15, n. 5, p. 172-186, 2014.

BELLUTA, I.; DOYAMA, J.T.; COELHO, J.C.; JESUS, S.A.; WONDRACEK, M.H.P.; CARVALHO, L.R.; CASTRO G.R. Contaminação por espécies metálicas em solos associados às rodovias: Botucatu SP, Revista Geociências, São Paulo, v. 37 , n. 2, p. 247-359, 2018

BELÓ, A.; QUINÁIA, S.P.; PLETSCH, A.L. Caracterização de sedimento superficial do rio Jordão na região Centro Sul do Paraná. Brasil. Revista Ambiagua, Taubaté, SP, v. 5, n. 1, p. 134-144, 2010.

BRAMORSKI, J. Avaliação da qualidade de sedimentos dos rios Tietê e Piracicaba nos seus compartimentos de entrada no reservatório de Barra Bonita SP. São Carlos. 2004, 134 p., Dissertação (Mestrado), Escola de Engenharia de São Carlos - Universidade de São Paulo.

BRANCO, S.M. Hidrobiologia aplicada à engenharia sanitária. CETESB, 620 p. 1978.

BRANDÃO, C.J.; BOTELHO, M.J.C.; SATO, M.I.Z.; LAMPARELI, M.C. (org.). Guia nacional de coleta e preservação de amostras: água, sedimento, comunidades aquáticas e efluentes líquidos. São Paulo: CETESB; Brasília: ANA, 2011. $326 \mathrm{p}$.

BUCHIMAN, M.F. NOAAS Creening Quick Reference Tables, NOAA OR \& R Report 08-1, Seatle WA, Office of Response and Restoriation Division, National Oceanic and Atmospheric Administration, 34 p. 2008.

CATI - COORDENADORIA DE ASSISTÊNCIA TÉCNICA INTEGRAL. Mapa Pedológico do Município de Botucatu. Adaptado do Mapa Pedológico do Estado de São Paulo. Escala 1:500.000. Instituto Agronômico de Campinas e Embrapa Solos, 1999.

CONAMA - CONSELHO NACIONAL DE MEIO AMBIENTE. Resolução no 344, de 25 de Março de 2004: estabelece as diretrizes gerais e os procedimentos mínimos para a avaliação do material a ser dragado em águas jurisdicionais brasileiras, e dá outras providências. Brasília (DF); Diário Oficial da União n ${ }^{\circ}$ 087, de 07/05/2004, p. 56-57.

COSTA, J.B. \& ESPÍNDOLA, E.L.G. Avaliação ecotoxicológica da água e sedimento em tributários do reservatório de Barra Bonita (Médio Tietê Superior, SP). In: ESPÍNDOLA, E.L.G.; PASCHOAL, C.M.R.B.; ROCHA, O.; BOHRER, M.B.C.; OLIVEIRA NETO, A.L. Ecotoxicologia: perspectivas para o século XXI. São Carlos SP, p. 75-93, 2002.

COTTA, J.A. O. Diagnóstico ambiental do solo e sedimento do Parque Estadual Turístico do Alto Ribeira (PETAR). São Carlos. 2003. 130 p. Dissertação (Mestrado), Instituto de Química de São Carlos - Universidade de São Paulo.

DUARTE, R.P.S. Avaliação do cádmio (Cd), chumbo (Pb), níquel (Ni) e zinco $(\mathrm{Zn})$ em solos e plantas às margens de uma rodovia de tráfego intenso de veículos. 2003, 127 p. Tese (Doutorado), Faculdade de Ciências Agronômicas, Universidade Estadual Paulista, Botucatu.

ESTEVES, F.A. \& GUARIENTO, R.D. Elementos-traço. In: ESTEVES, F.A. Fundamentos de limnologia. Rio de Janeiro RJ, p. 323-334, 2011.

FIGUEIREDO, E.M.M. Pontos críticos na caracterização físico-químicas das águas de escorrências de estrada Estudo de Caso do Projeto G-Terra. Viseu. 2011, 95 p. Dissertação (Mestrado). Escola Superior de Tecnologia e Gestão de Viseu. Viseu - Portugal.

GARCIA, C.M. \& SOTTORIVA, E.M. Poluição difusa urbana decorrente do desgaste dos freios automotivos: estudo de caso na sub-bacia do rio Belém, em Curitiba PR. Revista REDES, Santa Cruz do Sul RS, v. 15, n. 3, p. 5-25, 2010.

HAKANSON, L. An ecological risk index for aquatic pollution control, a sedimentological approach. Water Research, v. 14, n. 8, p. 975-1001, 1980.

HANN, W. \& JENSEN, P.A. "Water Quality Characteristics of Hazardous Materials". Environmental Engineering Division, v. 3, 1974

HOFF BRAIT, C.H. \& ANTONIOSI FILHO, N.R Desenvolvimento e aplicação de sistema passivo de coleta de poluentes atmosféricos para monitoramento de $\mathrm{Cd}, \mathrm{Cr}, \mathrm{Pb}, \mathrm{Cu}$, $\mathrm{Fe}, \mathrm{Mn}$ e Zn e particulados totais. Revista Química Nova, v. 33, n. 1, p. 7-13, 2010.

KABATA-PENDIAS, A. Trace elements in soils and plants, $4^{\mathrm{TH}}$ Ed., 2010

KELLER, C. \& VÉDY, J.C. Heavy metals in the environment: distributions of copper na cadmium fractions in two forest soils. Journal of Environmental Quality. Madison, v. 23, n. 5, p. 987-999, 1994.

LENNTECH - Lenntech Water Treatment Solutions. Disp. em: 〈EUA〉. Acesso em: 25 de Maio de 2017, http://www.lenntech.com/heavy-metals.htm.

MADONI, P. \& ROMEO, M.G. Acute toxicity of heavy metals towards freshwater ciliated protists. Environmental Pollution, v. 14, p. 1-7, 2006.

MALDONADO, A.C.D. \& WENDLING, B. Manejo de sistemas aquáticos contaminados por metais pesados. Agropecuária Técnica, Areia Pb, v. 30, n. 1, p. 21-32, 2009.

MARTINEZ, L L.G. Distribuição de poluição difusa por sedimentos urbanos em áreas impermeáveis em Porto Alegre. Porto Alegre. 2010, 90 p. Dissertação (Mestrado), Universidade Federal do Rio Grande do Sul.

MAZON, A.F.; PINHEIRO, G.H.D.; FERNANDES, M.N. Contaminação dos ecossistemas aquáticos pelo cobre e risco potencial à biodiversidade: estudo da toxicidade do cobre em curimbatá, $P$. scrofa (Teleostei, Prochilodontidae). In: ESPÍNDOLA, E.L.G.; PASCHOAL, C.M.R. B.; ROCHA, O.; BOHRER, M.B.C.; OLIVEIRA NETO A.L. Ecotoxicologia: perspectivas para o século XXI. São Carlos SP, p. 327-340, 2002.

MINELLO, M.C.S.; PAÇÓ, A.L.; MARTINES, M.A.U.; CAETANO, L.; SANTOS, A.; PADILHA, P.M.; CASTRO, G.R. Sediment grain size distribution and heavy metals determination in a damon the Paraná River at Ilha Solteira, Brazil. Journal of Environmental Science and Health, v. 44, p. 861-865, 2009

PEREIRA, E.; BAPTISTA-NETO, J.A.; SMITH, B.J.; Mc ALLISTER, J.J. The contribution of heavy metal pollution derived fron highway runoff to Guanabara Bay sediments - Rio de Janeiro Brazil. Anais Academia Brasileira de Ciências, Rio de Janeiro RJ, v. 79, n. 4, p. 739-750, 2007.

PIERANGELE, M.A.P.; GUILHERME, L.R. G.; CURI, N.; SILVA, M.L.N.; LIMA, J.M.; COSTA, E.T.S. Efeito do pH na adsorção e dessorção do Cádmio em latossolos brasileiro. Revista Brasileira de Ciência do Solo. Viçosa MG, v. 28, p. 523-532, 2005. 
POLETO, C. \& CARDOSO, A.R. Concentração de Zn e Ni em sedimentos urbanos de trinta cidades do Rio Grande do Sul: riscos aos recursos hídricos Estaduais. Revista Brasileira de Recursos Hídricos, Porto Alegre, v. 17, n. 3, p. 93-100, 2012. POLETO, C. \& MERTEN, G.H. Estudos de Zn e Ni em sedimentos fluviais em suspensão e o risco potencial aos recursos hídricos. Revista Brasileira de Recursos Hídricos. Porto Alegre, v. 13, n. 3, p. 147-154, 2008.

SANTOS, T.O.; VIEIRA, R.; SILVA FILHO, C. A.; HAZIN, C.A.; VALENTIN, E. Quantificação de elementos químicos associados ao tráfico de veículos de bromélias atmosféricas transplantadas na região metropolitana do Recife. Revista Scientia Plena, Sergipe SE, v. 9, n. 8, p. 1-8, 2013.

SILVA, E.P. Acúmulo e carreamento de metais pesados e sólidos em superficies asfálticas. Goiânia. 2014, 111 p Dissertação (Mestrado), Universidade Federal de Goias.

SOKAL, R.R. \& ROHLF, F.J. Biometry: the principles and practice of statistics in biological research. $3^{\text {rd }}$. ed. New York: W. H. Freeman, 1995.

SOSCUESTA - SOS CUESTA DE BOTUCATU. Córrego da Cascata: um rio limpo na area urbana de Botucatu Caracterização, recuperação e planejamento ambiental Botucatu SP, 259 p. 2013.

THE EUROPEAN PARLIAMENT AND OF THE COUNCIL OF THE EUROPEAN UNION. Directive 2000/60/EC. Off. J. Eur. Commun., p. L 327/1-72, 2000.
TORRES, A.M.; BASTOS, M.L.L.; BOAVENTURA, G.R.; LICHT, O.A.B.; KERN, D.C.; MELO JÚNIOR, G.; FRAZÃO, F.J.L.; COSTA, M.L.; BORBA, R.P.; FIGUEIREDO, B.R.A. Geoquímicados sedimentos e solos. In: SOUZA C.R.G.; SUGUIO, K.; OLIVEIRA A.M.S.; OLIVEIRA, P. E. Quartenário do Brasil. Ed. da USP, São Paulo, Cap. 14. p. 298-320, 2005.

VINHAL-FREITAS, I.C.; MALDONADO, A. C.D.; ALVARENGA, C.B.; CAMARGO, R.; WENDLING, B. Adsorção e dessorção de metais no solo e coeficientes de isotermas de Freundlich e Langnuir. Agropecuária Técnica, Areia PB, v. 31, n. 2, p. 153-163, 2010

YANNOPOULOS, S.; BASBAS, S.; GIANNOPOULOU, I. Water bodies pollution due to highways stormwater runoff: Measures and legislative framework. Global NEST Journal, Greece. v. 15, n. 1, p. 85-92, 2013.

Submetido em 18 de fevereiro de 2019 Aceito em 12 de maio de 2020 